\title{
Incorporation of Modeling, Simulation, and Game-Based Learning in Engineering Dynamics Education towards Improving Vehicle Design and Driver Safety
}

\author{
Kevin F. Hulme ${ }^{1, * \mathbb{D}}$, Mark Schiferle ${ }^{2}$, Rachel Su Ann Lim ${ }^{1}$, Aaron Estes ${ }^{2}$ and Matthias Schmid ${ }^{3}$ \\ 1 The Stephen Still Institute for Sustainable Transportation and Logistics, University at Buffalo, \\ Buffalo, NY 14260, USA; rlim2@buffalo.edu \\ 2 Department of Aerospace and Mechanical Engineering, University at Buffalo, Buffalo, NY 14260, USA; \\ ms286@buffalo.edu (M.S.); aaronest@buffalo.edu (A.E.) \\ 3 Department of Automotive Engineering, Clemson University, Clemson, SC 29634, USA; \\ schmidm@clemson.edu \\ * Correspondence: hulme@buffalo.edu; Tel.: +1-716-645-5573
}

check for updates

Citation: Hulme, K.F.; Schiferle, M.; Lim, R.S.A.; Estes, A.; Schmid, M. Incorporation of Modeling,

Simulation, and Game-Based Learning in Engineering Dynamics Education towards Improving Vehicle Design and Driver Safety. Safety 2021 7,30. https://doi.org/10.3390/ safety7020030

Academic Editor: Raphael Grzebieta

Received: 29 December 2020

Accepted: 29 March 2021

Published: 19 April 2021

Publisher's Note: MDPI stays neutral with regard to jurisdictional claims in published maps and institutional affiliations.

Copyright: (c) 2021 by the authors. Licensee MDPI, Basel, Switzerland. This article is an open access article distributed under the terms and conditions of the Creative Commons Attribution (CC BY) license (https:/ / creativecommons.org/licenses/by/ $4.0 /)$.

\begin{abstract}
As educational tools continue to evolve technologically, game-based learning (GBL) has emerged for its ability to improve specific learning outcomes such as motivation, engagement, and knowledge acquisition and retention. Despite recent advances with educators incorporating games and gaming strategies into higher-learning curricula, there is a current void in the literature that clarifies the critical relationship between GBL implementations and learning outcomes. In this effort, we build upon previous research by detailing the specification, design, and deployment of a series of GBL experiential learning interventions intended to improve conceptual understanding of vehicle dynamics. This implementation should result in positive downstream impacts on safety, both for the vehicle (i.e., design/interface)—and its driver. In our intervention, we deploy three separate pilot studies in a graduate engineering vehicle dynamics course, all of which leverage advanced GBL environments deployed on a high-fidelity motion-based driving simulator. The primary goals of the pilot studies are to interactively achieve an enhanced understanding of: (i) oversteer/understeer vehicles at ever-increasing speed; (ii) an optimal cornering strategy subject to the tire conditions of the vehicle; and (iii) lateral handling and yaw stabilization of a vehicle within an extreme evasive maneuver at varying entry speeds. The outcomes of the current effort serve to promote a future Theory of Change for planned best practices to improve human factors and human-vehicle machine interfaces through authentication of GBL in engineering education on a broader scale.
\end{abstract}

Keywords: vehicle dynamics; engineering education; vehicle design engineering; vehicle safety; driver safety; game-based learning; gamification; learning outcomes; experiential learning; modeling and simulation (M\&S); motion simulation; driving simulation

\section{Background}

Motor vehicle travel remains the primary mechanism for transportation in the United States, and continues to provide and enable an unprecedented flexibility for human mobility [1], including persons, goods, and services. However, despite the obvious advantages of ground transportation, deaths and injuries resulting from motor vehicle travel continue to be a leading cause of mortality for persons across all age demographics [2]. It has been previously estimated [3] that upwards of $90 \%$ of all negative driving outcomes are the direct result of some form of human error, and therefore, it remains a national priority to reduce deaths, injuries, and economic losses from motor vehicle crashes [1]. While the immediate future holds great promise for improving vehicular safety through widespread deployment of connected and automated vehicles, (a) both the performance and human acceptance (i.e., "trust") of advanced automation vehicle systems remains unclear; (b) automated vehicles 
can be misused (e.g., challenges related to information management and cybersecurity); and, prominently, (c) intelligent automation only serves to transfer the burden of error from "human to human"; i.e., from the vehicle driver to the vehicle designer [4].

As a direct result of these timely published statistics and alarming public health trends, subject-matter experts in engineering education continue to emphasize the critical importance of providing students - and tomorrow's technological leaders-with authentic and engaging classroom experiences that enrich and enhance our understanding of the real world. To this end, particularly effective are learning experiences that effectively cultivate realistic modeling and high-fidelity simulation [5], which together enable real-time observation of downstream impacts (cause/effect) on a complex system representation [6]. Within the discipline of transportation engineering (i.e., and particularly within the sub-domains of dynamics and controls), effective and engaging learning experiences can incorporate authentic and physics-based mathematical models and accompanying simulations into conventional instructional methods. These implementations will serve to better clarify the abstract nature and true behavior of highly-interdisciplinary systems (e.g., motor vehicles) with concrete hands-on examples [7] that more effectively bridge the gap between experimentation and implementation; between basic theory and real-world application $[8,9]$. Such educational pathways remain essential towards the systematic improvement of vehicle design, and-as a result-sustainable, long-term trends that are most likely to result in dramatically improved vehicle (and driver) safety.

Engineering students within these sub-disciplines who have been afforded opportunities to cultivate virtual hands-on experiences in addition to traditional "chalk and talk" classroom exercises have demonstrated numerous benefits. These include improved academic performance $[10,11]$, engineering job performance $[12,13]$, and practical skill sets that remain highly-coveted by industry [14]. The effectiveness of hands-on, or "experiential" exercises is often attributed to its roots in inductive (active) learning-which begins with specific observations, experiments, or problems that students experience and analyze, and proceeds to the generalization of these observations within an abstract or theoretical framework [15]. Within the virtual simulation realm, hands-on learning effectively combines system synthesis and analysis through interactive tools which empower students to: (a) modify modeled system parameters, (b) experience resulting system behavior, and (c) subsequently monitor impact/response "on-the-fly", and in real-time [16].

Such educational avenues continue to become increasingly attractive to educators for improving practical experience, as today's youth are more immersed in gaming. Gamebased learning (GBL) is where trainees explore relevant aspects of gaming in an educational and collaborative context, and often experience enhanced engagement in such environments [17-19]. GBL has continually proven to be a convenient domain where students can safely interact with authentic problems, similar to in a real-life setting. Serious gaming (i.e., employing traditional game techniques and "gameplay" to enable a better understanding of a particular concept), gamification (i.e., employing game mechanics in non-game situations to enhance motivation and positively influence behavior) [20], and the overarching notion of serious play-employing task-specific interactions by simulating scenarios in risk-free physical/virtual environments $[21,22]$ all serve to motivate learners and effectively couple the novelties of entertainment into a safety-driven context for skill acquisition.

In this paper, we build upon past literature and present a series of targeted interventions intended to demonstrate the benefits of incorporating advanced modeling and simulation (M\&S), and game-based learning (GBL) into existing engineering curricula. In this effort, our disciplinary focus remains with vehicle dynamics and system control, and therefore, applications relevant to transportation engineering. Figure 1 presents a notional overview of the overall flow of this paper, and emphasizes the various highlights and novelties of this work. Having now justified the benefits of advanced M\&S and GBL in engineering education from previous literature, our research methodology provides an overview of our three novel GBL interventions and pilot studies that were implemented for this work. After that, we present our preliminary results and summarize the major 

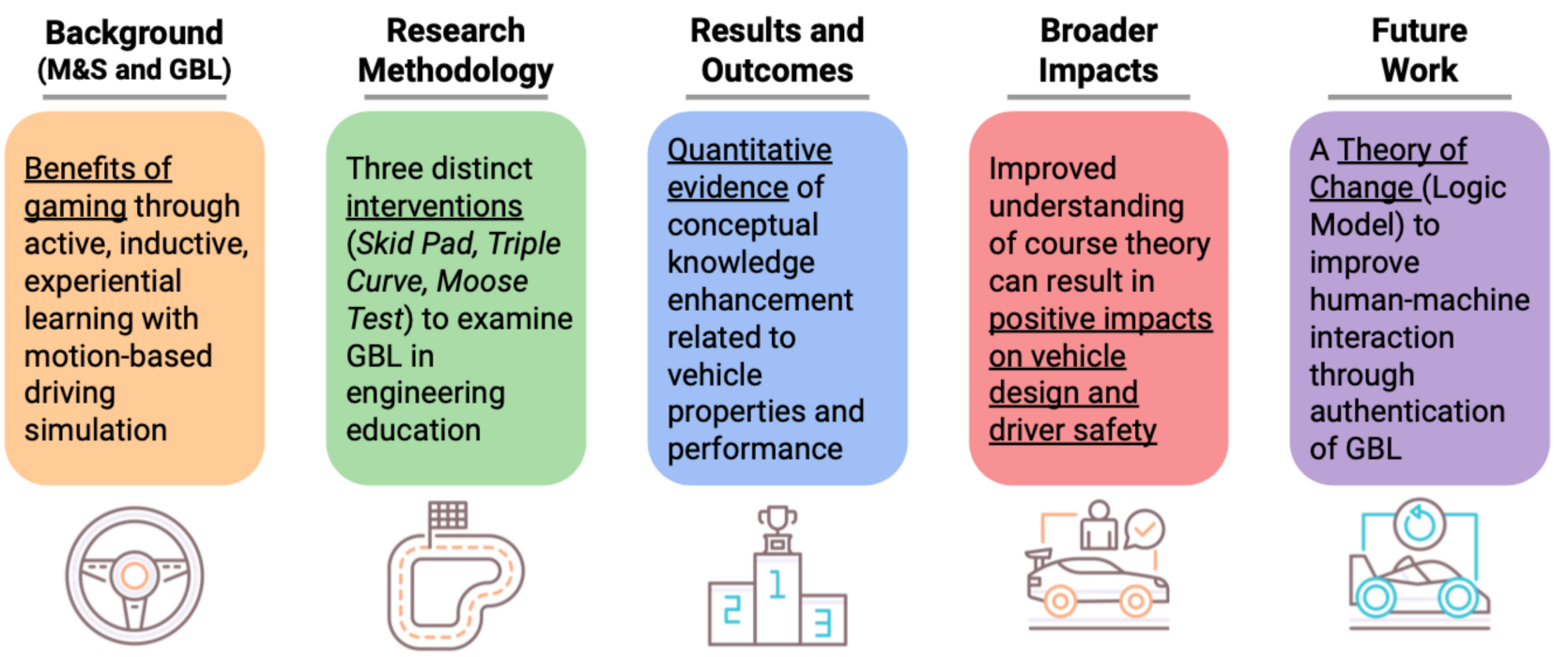

Figure 1. Overall workflow of current effort.

\section{Research Methodology}

Recent research has demonstrated that through imparting thoughtful experimental design approaches (i.e., with elements of gaming, and hands-on inductive learning), driving simulation performance correlates strongly with real-world knowledge and skill-acquisition. Drivers have been found to navigate similarly for companion on-road and virtual courses with marginal statistical difference in behaviors (e.g., speed maintenance, hazard anticipation, attention maintenance, lane positioning, and mirror checking) [23-26]. Simulators have further been implemented successfully for identifying and improving the skill of older adult drivers through targeted training exercises, and such implementations are considerably safer and more economical than on-road testing and evaluation [27-29]. Because of these advantages, motion simulation has more recently been implemented to develop and verify human driver models in extreme driving situations, such as evasive maneuvers, as well as classifying different types of drivers (e.g., cautious or aggressive) and mimicking human driving behavior [30,31] within a mathematical framework [32].

Past engineering research [33] has successfully demonstrated the inclusion of gamebased M\&S educational elements as a core component. A prevailing theme has been to incorporate novel high-fidelity driving simulation into engineering curricula to offer improved techniques for driver education and traffic safety. Likewise, a novel component of recent efforts has been to leverage multiple measure types (e.g., quantitative, qualitative, self-report, longitudinal) to assess trainee performance, assess knowledge transfer, and rate instructional preferences [34]. These research efforts serve as a direct precursor to the current work, as they demonstrated an educational framework wherein learners optimized vehicle performance through factor parametrization.

The lynchpin for our research methodology is on the infusion of advanced M\&S and GBL within the domain of transportation engineering for road vehicle dynamics education. Furthermore, our framework for systematically instituting a series of "official" proving grounds test, track configurations, and vehicle maneuvers for experiential learning provides a uniquely authentic opportunity for hands-on real-world training, and serves as a substantial improvement over related efforts from the literature. If successfully demonstrated and implemented in this context, GBL can substantially enhance passive classroom 
instruction, and nurture a deeper understanding of the physical feel of the dynamics of a vehicle under specified conditions. These inherent benefits could result in positive downstream learning outcomes among engineers in training, including critical acquired skills for vehicle engineering design (e.g., control systems, vehicle stability systems), as well as an enrichment of knowledge relating to vehicle operation in "extreme" conditions, both of which serve to improve transportation and roadway safety in the long term.

Note that this study was approved on 16 August 2018 by the ethics committee of 030 University at Buffalo Institutional Review Board (IRB) with the code STUDY00002749.

\subsection{Experimental Facilities and Design}

Our high-fidelity driving simulator provides a valid test environment for game-based learning in engineering dynamics education, and to accommodate gamification-based human performance measurement within a variety of driving scenarios. For a notional summary of our input/output (I/O) pipeline, refer to Figure 2; for additional technical details, refer to [35].

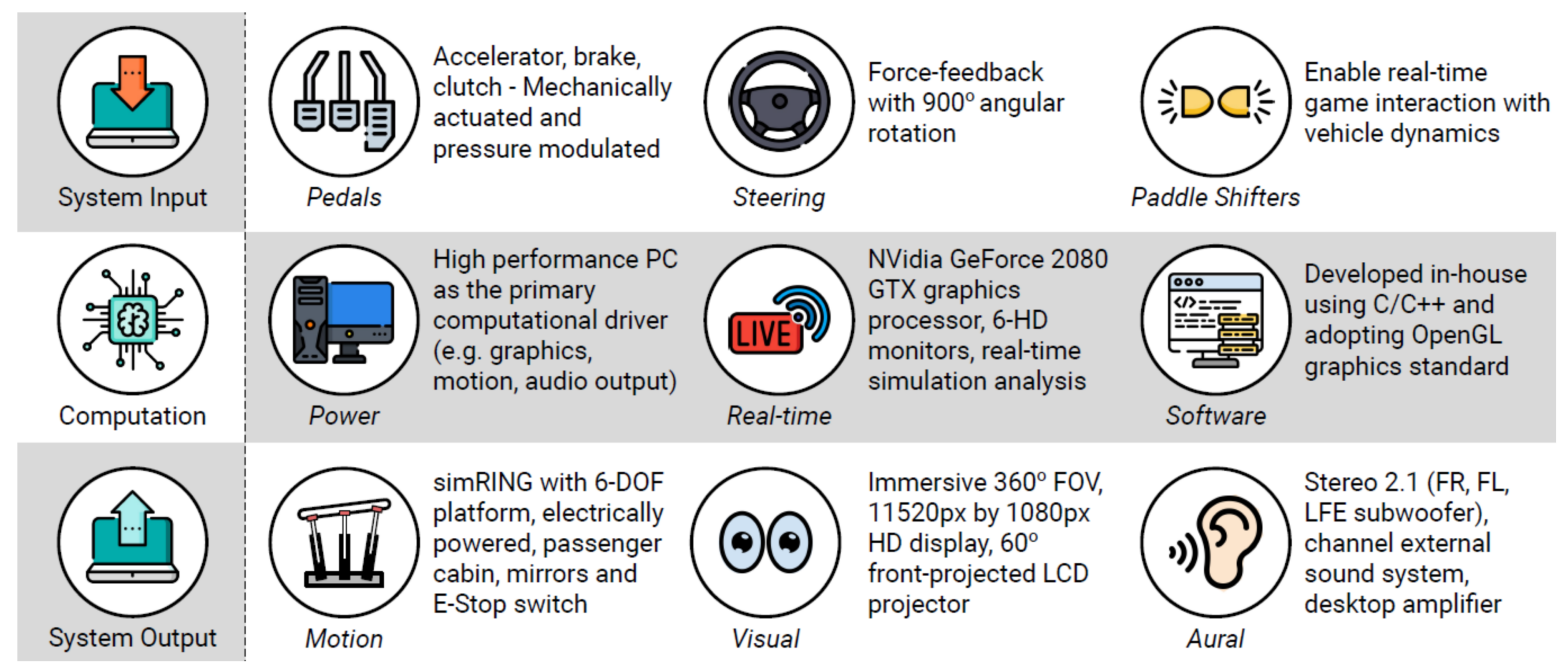

Figure 2. Input/output (I/O) rendering components for game-based learning (GBL) in engineering dynamics education.

Our hardware system has been constructed largely in-house, using commodity hardware, and is anchored by a six degree-of-freedom electrically actuated motion platform (and a driver/passenger Ford Sedan cabin) manufactured by Moog, Inc. (East Aurora, NY, USA). The driver supplies inputs using a spring-resisted steering wheel, rear-wheel paddle shifters (for parametric adjustments during the driving interventions), and pressuremodulated floor pedals (gas, brake). Our fully-immersive display system consists of a continuous cylindrical $16^{\prime}$ diameter, $6^{\prime}$ high display screen mounted such that the screen center lies at the approximate midpoint of the driver's viewpoint. Each of the six visualization channels is front-projected with an HD LCD projector, featuring a widescreen ultra extended graphics array $(W U X G A ; 1920 \times 1080)$ resolution. When the scene graphics are edge-blended and warped to the curved surface of our cylindrical display plane, the resulting cumulative display resolution is 11,520 (circumference) $\times 1080$ (height) pixels. For aural cueing, we employ a stereo 2.1 (front-left, front-right, and subwoofer) channel external sound system powered by a desktop audio amplifier. A single PC (CPU/GPU) drives our entire simulator arrangement, consisting of a tower graphics workstation with dual-core 2.16 GHz Intel Xeon processors, 16 GB Memory, and an GeForce 2080 GTX graphics processor, manufactured by Nvidia (Santa Clara, CA, USA). Our simulator (software) environment was developed in-house, using Microsoft Visual Studio and C++. Our programming framework includes DirectX DirectInput for input capture, as well as OpenGL (graphics), OpenAL (audio), and TCP/IP Sockets and Win32-ported Posix multithreading 
(motion) for output rendering. Likewise, refer to Figures 3 and 4 for depictions of our physical simulator arrangement.

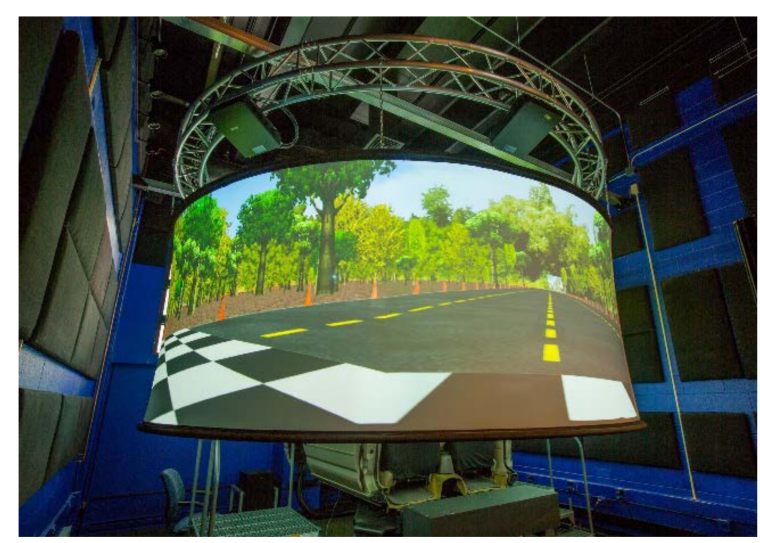

Figure 3. Simulator (display system).

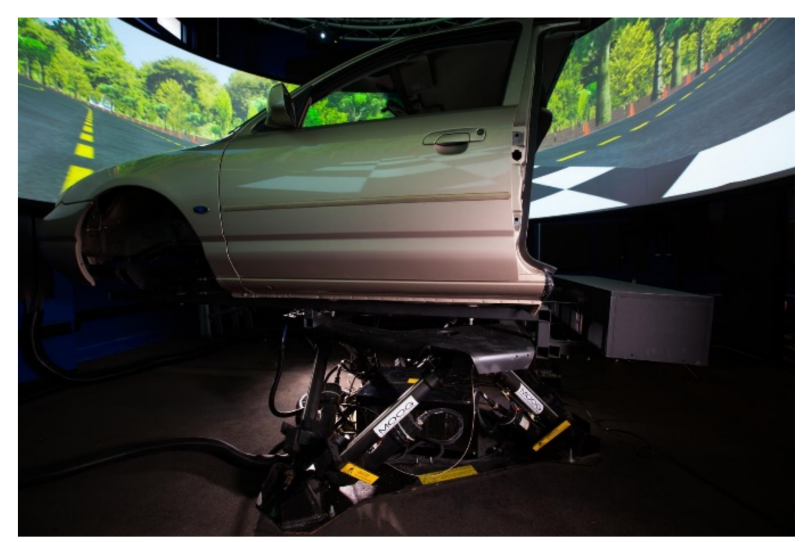

Figure 4. Simulator (motion platform).

For all three experimental GBL interventions that were specified, designed, and implemented for this work, we programmed the simulator to collect a series of quantitative data, including the drive path coordinates for each driver during their entire excursion (captured at $20 \mathrm{~Hz}$ ) as well as a score sheet printout that summarizes primary statistics from each driving experiment (e.g., steering wheel and foot pedal inputs, lap counters, maximum and average speed, force, acceleration, and other engineering dynamics data specific to each intervention, and other measured driver actions and behaviors that result in adverse events, such as cone strikes or vehicle spinouts).

\subsection{Skid Pad Intervention}

A skid pad [36] is a classic proving ground facility that consists of a circular track with a defined radius. A skid pad is typically used to determine the "understeer gradient" of a vehicle, as well as its maximum lateral acceleration capabilities. During a skid pad test, a vehicle is slowly and steadily accelerated until it reaches a cornering speed where the outermost tires on the vehicle begin to lose traction. For an "understeer" vehicle, increasing speed beyond this threshold causes the front tires to start sliding, creating a "plowing" trajectory toward the outside or the skid pad. For an "oversteer" vehicle, the rear tires start sliding, which can cause the vehicle to spin nose-inward. In either case, the net lateral force of the tires can no longer hold the vehicle in the corner, and the driver must decrease speed to regain control. At this juncture, the speed of the vehicle can be recorded, and based upon the well-known equation for centripetal acceleration $\left(\mathrm{v}^{2} / \mathrm{r}\right)$, the "handling" capabilities of the vehicle (i.e., in terms of lateral G-forces) can be derived $[37,38]$. The maximum centripetal acceleration a vehicle can produce, as well as the 
understeer/oversteer characteristics, are primarily a function of the relative lateral stiffness of the front and rear tires (i.e., the cornering stiffness) and the frontal weight distribution of the car. Refer to Figure 5, which depicts a real-world (physical) skid pad facility located at the BMW Performance Center.

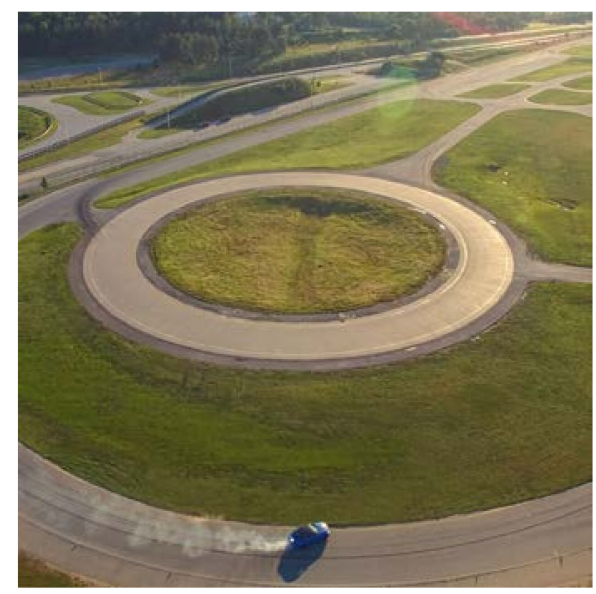

Figure 5. Skid pad (BMW Performance Center).

Our GBL skid pad [39] interactively teaches students about the understeer and oversteer characteristics of road vehicles, and specifically how these characteristics depend on the longitudinal position of the vehicle's center of gravity (CG), or weight distribution. A radius on the skid pad is clearly specified for the students to follow. In addition to being able to steer, brake, and accelerate, the students are able to utilize wheel-mounted paddle shifters to adjust the longitudinal CG position of the vehicle. Changing the CG position modifies the handling characteristics of the vehicle, and therefore its maximum speed potential while cornering. Moving the CG toward the front of the vehicle increases understeer characteristics, and stabilizes the vehicle's yaw motions; whereas moving the CG toward the rear of the vehicle increases oversteer characteristics, and destabilizes the vehicle's yaw motions. Both configurations result in a sub-optimal maximum cornering speed. Hence for optimality, trainees need to modify the CG position towards the intermediate "neutral steer" condition. In our GBL experiment, students were given two minutes to achieve this goal, all the while increasing speed to go as fast as they could while remaining on a constant-radius circular trajectory.

Within the simulator, identifying neutral steer involves intuitive adjustment of the CG by kinesthetic "feel" and discovery to comprehend its resulting impact upon overall vehicle handling. Note that embedded within our GBL skid pad, we designed and implemented on-screen gaming elements to guide the learner towards their training goal (i.e., neutral steer) — which typically permits an optimal balance of maximum speed and vehicle control. These gaming elements are explained as follows:

The steering wheel indicator visually quantifies how much drivers are turning their hands, noting that at neutral steer, trainee steering is reduced (i.e., hands in a fixed-position).

The travel speed gauge guides drivers towards obtaining their optimum speed on the chosen radius, guided by green/yellow/red color-coding, while the current travel speed is shown digitally to the right of the contour gauge.

The (CG) and tire stiffness distribution meter guides trainees towards a "balanced" vehicle based upon tire/weight distribution, front-to-rear. The meter tire colors change relative to their individual saturation levels, ranging from $0 \%$ (unsaturated; green) to $>6 \%$ (saturated/beyond; red), to intermediate (e.g., yellow/orange).

The radar map displays the current location (and heading) of the driven vehicle relative to the roadway, surrounding cones, and remainder of the GBL virtual world training map. 
The heading pathway lies within the 3D viewport itself, and can be seen a series of colored spheres that guide the driver and change color in real-time according to compliance: green represents on-center; red indicates far off-center, with intermediate colors (e.g., yellow/orange) indicating partial pathway satisfaction.

The scoring meter was implemented to provide an overall gamification "rating" (0-100\% scale) based on compliance to speed, heading, and neutral steer proximity. This "rewards" system was instituted to engage and motivate drivers to comply with the goals of the experiment in direct pursuit of its primary training objective.

Refer to Figure 6, which illustrates the forward driver view of the completed skid pad GBL training environment, with all gaming elements depicted and labelled. Likewise, Table 1 provides a summary of the skid pad intervention and its surmised broader impacts on transportation safety.

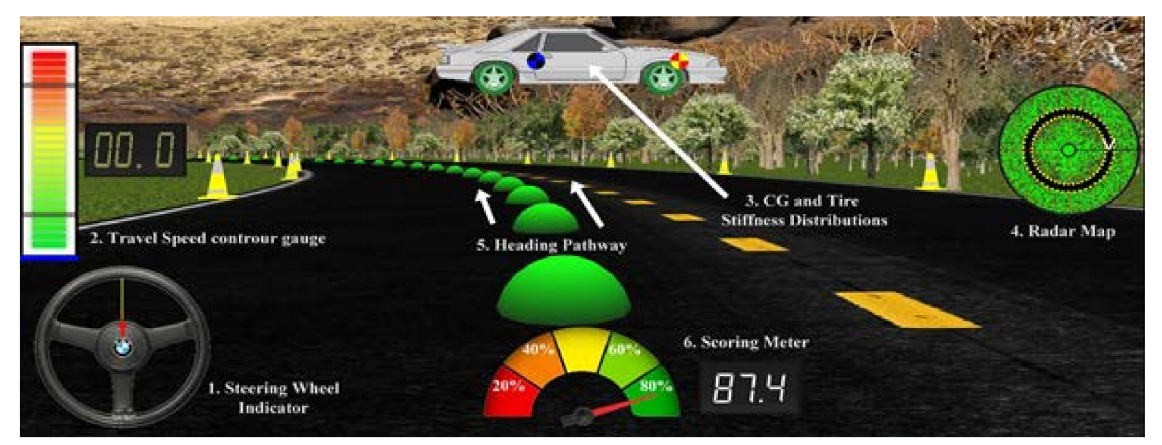

Figure 6. GBL skid pad implementation (with embedded gaming elements).

Table 1. Skid pad (experiment summary).

\begin{tabular}{ll}
\hline Track & Circular proving grounds. \\
\hline Training goal & Vary the CG to optimize understeer characteristics of vehicle. \\
\hline Theoretical underpinning & "Natural steer" provides balance of stability/maneuverability. \\
\hline Trainer & $\begin{array}{l}\text { Six GBL elements navigate the trainee towards } \\
\text { concept comprehension. }\end{array}$ \\
\hline Broader Impacts on Safety & $\begin{array}{l}\text { Students gain an improved understanding of the complex } \\
\text { balance between a vehicle's (fore-aft) weight distribution, } \\
\text { front/rear tire stiffness, oversteer/understeer characteristics, } \\
\text { and how this combination of factors affect a vehicle's } \\
\text { dynamics when its cornering limits are approached. }\end{array}$ \\
\hline
\end{tabular}

\subsection{Triple Curve Intervention}

A triangular racetrack can be a useful resource to analyze vehicle dynamics, as in stark contrast to a traditional "oval" course, a triangle is a six-turn (as opposed to a four-turn) geometry, which provides a unique set of driving challenges (i.e., more turns, straightaways, and transitions between these key segments) to achieve mastery, even for experienced drivers. From the perspective of onlookers, a triangular layout better enables a greater number of longitudinal sightlines - an angular perspective of vehicles coming from (or going towards) a particular vantage point. Figure 7 is a real-world depiction of precisely such a construct (the Pocono Raceway), which is otherwise known as the "Tricky Triangle" due to its complex geometry (i.e., flat track; sharp turns; low banking).

Inspired by the triangular racetrack depicted in Figure 7, the GBL Triple Curve [37] is constructed with novice learners in mind, and therefore, is a simplified (i.e., completely axisymmetric) version that consists of three straight segments joined by three tight $\left(120^{\circ}\right)$ corners. Students are given simple directions: to complete as many legal laps (i.e., no barrier cones struck) as possible within a two-minute window. This task implies that the students maximize their speed, but maintain control of the vehicle during the critical transitions 
(i.e., straight-to-curve; curve-to-straight), for which students quickly learn that braking is essential for both speed and control. The conceptual training link is "tire saturation": the property that tires generate a limited amount of traction before the vehicle loses control (and skids out). To achieve an optimal lap time, the student needs to accelerate as much as possible, but only within the physical limitations of the tires. This is especially important in corners, where tire traction provides the centripetal force to hold the vehicle in the corner, and when the tractional demands increase in proportion to the square of the speed of the vehicle. Within our GBL implementation, the length of the straight segments allows students to accelerate to approximately $80 \mathrm{mph}$ before entering each successive corner. However, entering the tight corners at this speed (without smooth braking) will likely result in an undesirable outcome. Therefore, to make it through this track with the fastest speed, students must apply braking as they enter corners. The simple geometry of the track, by design, requires students to assume the same corner over and over again, adjusting their approach with each entry, each time engaging with the physics of tire saturation.

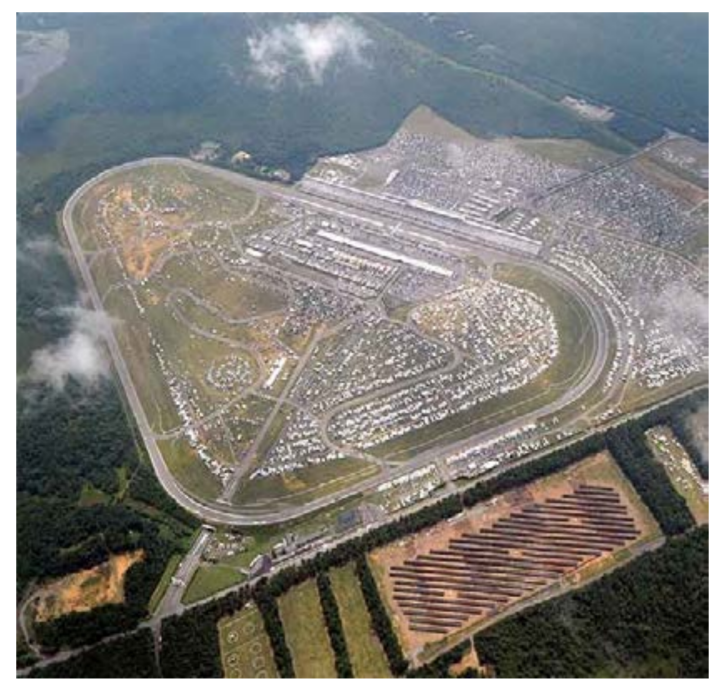

Figure 7. Triple Curve. (Pocono raceway).

We designed and implemented gaming elements to guide the learner towards their ultimate training goal (i.e., number of legal laps)—and therefore—an optimal lap time. We employed two training approaches for the Triple Curve experiment. First, our GBL-based "gauge" trainer enables visualization of technical guidance to observe if certain learners might respond to game-based on-screen overlays that would help them navigate towards optimized performance. These "gauges" include color-coded spheres placed upon the virtual roadway to simultaneously provide indication of the optimal drive line, as well as colors to indicate regions of acceleration (green), braking (red), and transition segments (yellow). Likewise, a vertical gauge was provided (left side of screen) to indicate the maximum tire slip angles encountered during a turn. The green region (low on the gauge) is indicative of overcautious driving; the red region (high on the gauge) is indicative of reckless driving; and the yellow region (middle of gauge) is the "sweet spot" that we inspired novice drivers to try to achieve during their turns. Refer to Figure 8a, which illustrates the gauge-training environment. Second, our "ghost" trainer was designed with a "follow the leader" gaming strategy in mind. In other words, rather than trying to coach novice trainees on the technical nuances of the racecourse, we simply instructed them to refer to the expert (prerecorded) "ghost" vehicle that would accompany them on their drive. In this manner, we aimed to assess if trainees could achieve effective training by watching/observing, and without any other visual presentation relating to the actual performance dynamics of the moving vehicle. Refer to Figure $8 b$, which illustrates the ghost trainer shown in the red vehicle on the right side of the forward viewport. Table 2 
provides a summary of the Triple Curve intervention and its surmised broader impacts on transportation safety.

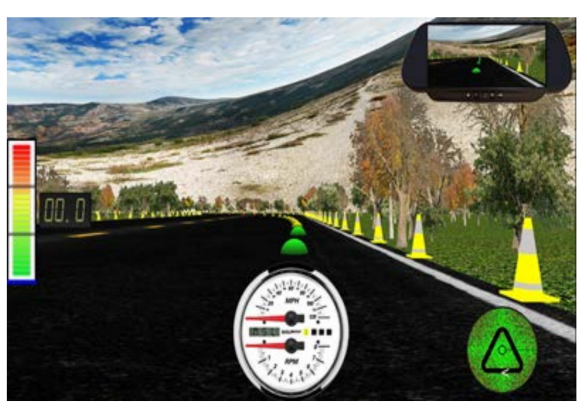

(a)

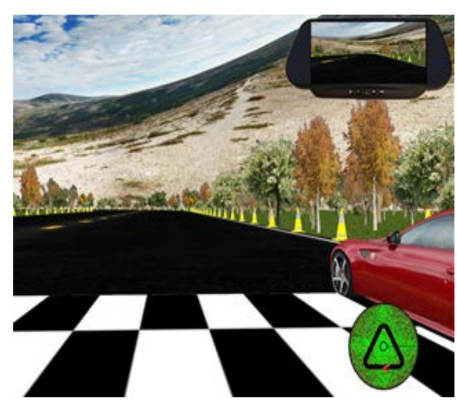

(b)

Figure 8. GBL Triple Curve implementation. ((a) gauge/left vs. (b) ghost/right trainers).

Table 2. Triple Curve (experiment summary).

\begin{tabular}{|c|c|}
\hline Track & $\begin{array}{l}\text { Triangular/axisymmetric; three straights joined by three tight } \\
120^{\circ} \text { corners. }\end{array}$ \\
\hline Training goal & $\begin{array}{l}\text { Maximize legal laps (i.e., no barrier cones struck) within a } \\
\text { two-minute window. }\end{array}$ \\
\hline Theoretical underpinning & Maximize acceleration within tire limitations; cornering is key. \\
\hline Trainer \#1 (Gauge) & $\begin{array}{l}\text { Visual guidance to navigate trainees towards ideal } \\
\text { course compliance. }\end{array}$ \\
\hline Trainer \#2 (Ghost) & $\begin{array}{l}\text { Trainees "follow the leader" to observe/replicate an optimal } \\
\text { racing line. }\end{array}$ \\
\hline Broader Impacts on Safety & $\begin{array}{l}\text { Students engage with the delicate balance of throttling, braking, } \\
\text { and steering during the transition from a straight to a corner. } \\
\text { Each of these driver "inputs" creates tractional demands for the } \\
\text { tires, which, if applied simultaneously, can push a tire to its limits; } \\
\text { combining braking and steering can easily saturate a tire's lateral } \\
\text { force capabilities at higher speeds (or even at lower speeds on a } \\
\text { wet or icy road). The simulator exercise affords students the } \\
\text { opportunity to encounter this tractional limitation of vehicles in a } \\
\text { safe setting. }\end{array}$ \\
\hline
\end{tabular}

\subsection{Moose Test Intervention}

In critical instances when drivers face unusual or hazardous driving conditions (e.g., inclement weather, high speeds, bumpy roads, vehicle malfunction, evasive reactions to sudden lateral events), we expect our vehicles to respond predictably and safely-and as advertised by the manufacturer. Before a vehicle is available on the market, it has to be tested in extreme conditions to ensure that no manufacturing defects or engineering design miscalculations (e.g., structural, aerodynamic) will result in unsafe or unpredictable performance. The Moose Test is a prime example of a proving ground evasive maneuver [40] and was conceived and configured to evaluate vehicle tilt stability (i.e., resistance to rollovers) and related handling performance, which play a critical role in assessing vehicle design and safety [41]. To standardize and simplify this lane change maneuver, the Association of the German Automotive Industry (VDA) revised the Moose Test, and transferred it to the International Standard ISO 3888-2 [42] allowing for reproducible test results. Refer to Figure 9, which illustrates an actual ISO 3888-2 Moose Test experiment as performed by the Nissan Corporation. 


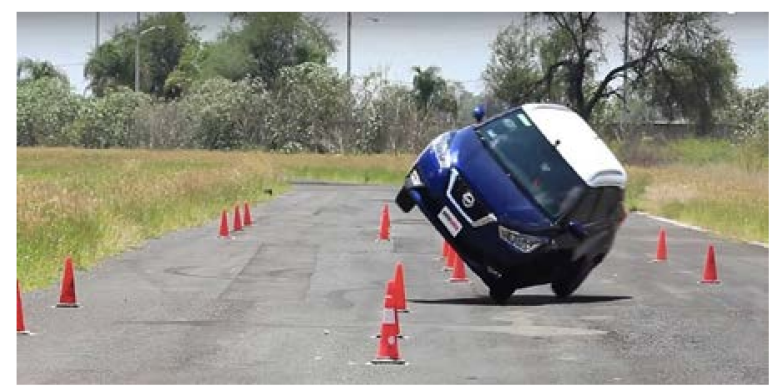

Figure 9. ISO 3888-2 Moose Test (Nissan Corporation).

Note that two configurations of the Moose Test exist ("original" and "modified"), each consisting of three lanes that have cones on either side. The lanes are arranged so as to induce a double lane change maneuver that has to be completed while coasting with a specified starting velocity. The time taken for the vehicle to complete the test course is measured starting from throttle release in the entry lane to when the vehicle passes the exit lane. The primary variations in the two test tracks consist of dimensional differences that aid in providing unique testing conditions. Taken together, the two Moose Test variants provide comprehensive data that can be used to holistically evaluate vehicle performance under extreme lateral accelerations. Figure 10 is an illustration of the "modified" configuration.

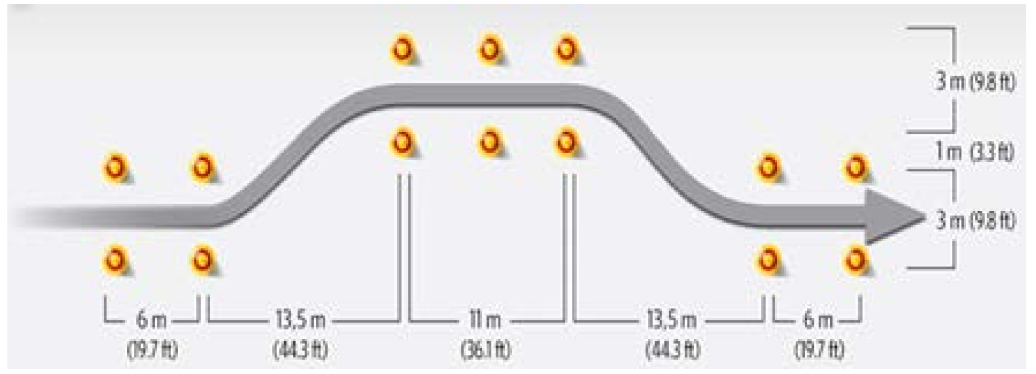

Figure 10. ISO 3888-2 ("modified") Moose Test configuration.

For our GBL Moose Test implementation [43], students were tasked to complete a grid of experimental test conditions, where three parameters were varied: (a) moose course (original vs. modified); (b) approach speed (20/30/40 mph), and (c) electronic stability controller (ESC) ("on" or "off"). The ESC simulated an electric "steer-by-wire" safety feature for yaw (heading) stabilization. Such a controller modifies the steering angle at the front tires, $\delta$, according to Equation (1).

$$
\delta=\delta_{\text {driver }}+\delta_{\text {steer-by-wire }}
$$

where $\delta_{\text {driver }}$ is the raw steering command provided by the driver, and $\delta_{\text {steer-by-wire }}$ is the steering modification provided by the ESC. As implied by the equation, notionally, with the presence of the ESC, a similar steering output is achieved with less (cumulative) steering input by the human operator during an evasive steering maneuver. The steering correction, $\delta_{\text {steer-by-wire, }}$ continuously updates such that the vehicle yaw rate and sideslip angle are stabilized about the "intended" path of the driver. This intended path is deduced by the ESC, according to the driver's steering angle, $\delta_{\text {driver }}$. When yaw moment disturbances are introduced to the vehicle by a loss of traction at one or more tires, steering corrections are automatically provided by $\delta_{\text {steer-by-wire }}$ to help prevent the vehicle from diverging from the intended path. In this way, the ESC assumes primary responsibility for rejecting disturbances that might cause the vehicle to lose control (e.g., during a skid), and the driver focuses on charting an intended path for the vehicle. Such automated systems generally increase the stability and safety of road vehicles, and are becoming more commercially popular [44-46]. 
In all, there were twelve total combinations of drive parameters (course x2; speed x3; controller $\mathrm{x} 2$ ) in our experimental grid. Table 3 provides a summary of the Moose Test intervention and its surmised broader impacts on transportation safety.

Table 3. Moose Test (experiment summary).

\begin{tabular}{ll}
\hline Track & $\begin{array}{l}\text { Straight-with a geometrically-specified double-lane-change } \\
\text { maneuver (ISO 3888-2). }\end{array}$ \\
\hline Training goal & $\begin{array}{l}\text { Experience the Moose Test amidst 12 varying } \\
\text { experimental conditions. }\end{array}$ \\
\hline Theoretical underpinning & $\begin{array}{l}\text { Observe impact of yaw stabilization with three } \\
\text { influential parameters. }\end{array}$ \\
\hline Trainer & $\begin{array}{l}\text { Physically accurate GBL "original" and "modified" road } \\
\text { course implementations. }\end{array}$ \\
\hline Broader Impacts on Safety & $\begin{array}{l}\text { Students experience the performance of a vehicle during a harsh } \\
\text { evasive maneuver with and without the aid of electronic stability } \\
\text { control. This comparison helps young engineers develop an } \\
\text { understanding of how (and to what extent) such an assistive } \\
\text { controller can help or harm drivers in extreme situations. }\end{array}$ \\
\hline
\end{tabular}

The primary objectives of the Moose Test experiment were to (a) expose engineering dynamics students to an official ("real-world") extreme vehicle test maneuver by employing GBL simulation to enhance their overall conceptual understanding; (b) employ high-fidelity simulation as a means of enhancing the educational experience of engineers; and (c) explicitly observe the degree of impact of employing a potential impactful safety feature-electronic stability control (ESC)—on driver performance at various speeds and geometric conditions. Figure 11 is a depiction of our GBL implementation shown "point of view" (POV), while Figure 12 presents an isometric top-viewpoint of the "modified" GBL road course.

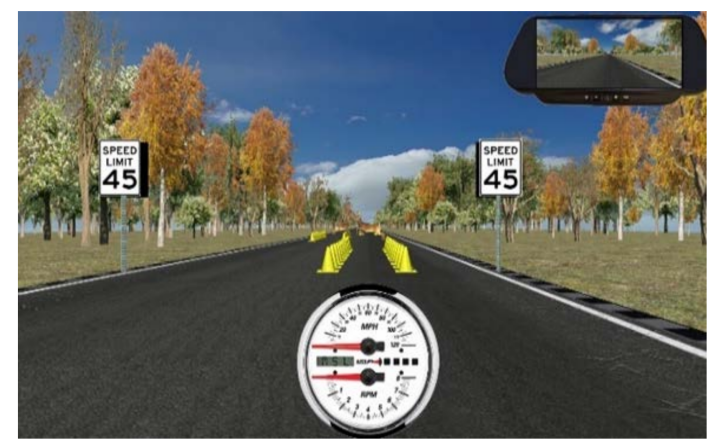

Figure 11. GBL Moose Test (point of view (POV)).

Insights gained from these GBL interventions during vehicle performance threshold and other "extreme event" scenarios can advise how the operation of next-generation vehicles-and forecasted mechanisms for operator intervention-can be tailored to individual differences (e.g., age, gender/demographics, driving experience, aggressive tendencies, past history) within specific driver types. For example, within a properly functioning autonomous system, safe distance between platooning vehicles can theoretically be minimized towards a near-zero spacing gap. However, based upon human tolerances and driver experience, what is the minimum headway that individual drivers can "tolerate" (i.e., based on workload, confidence, comfort, safety and acceptance)? Past results [47,48] demonstrate that most drivers prefer spacing between vehicles by relying on their judgment on distance, rather than on headway (time). As such, simulator-based efforts [49] to identify human tolerances have the potential to accelerate adoption, and maximize both safety and effectiveness of tomorrow's vehicles, and tomorrow's drivers. 


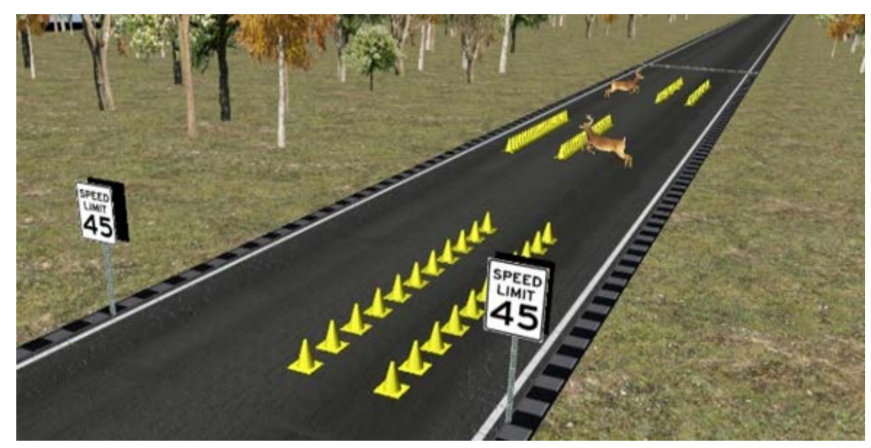

Figure 12. GBL Moose Test (isometric view).

As a final summary of our overall research methodology, we present Figure 13, which serves to illustrate and compare the primary performance and vehicle safety implications of our three experimental interventions. This summary serves as an ideal bridge into our preliminary findings and results, which are discussed in the next section.

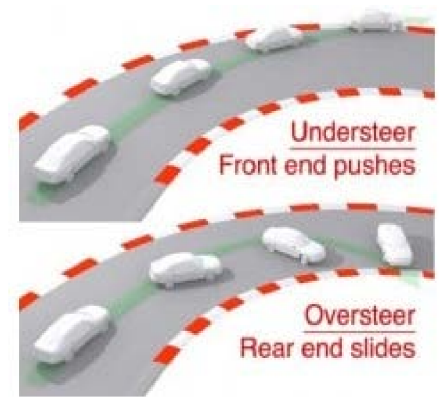

(a)

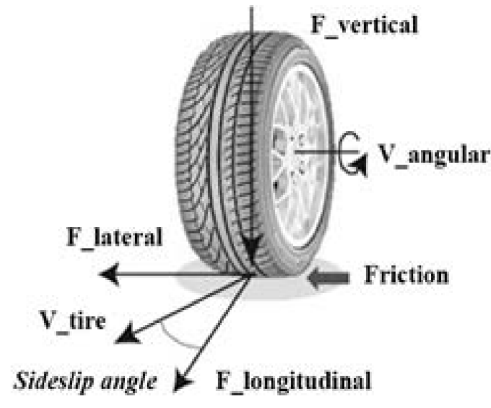

(b)

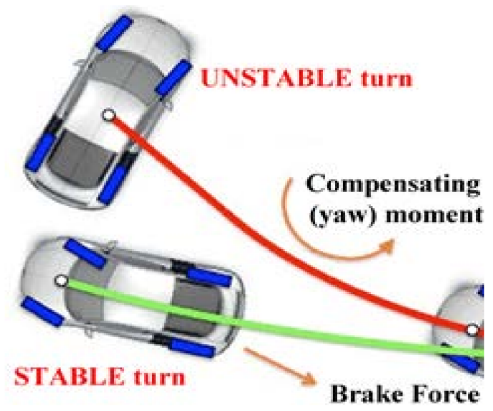

(c)

Figure 13. Summary of theoretical underpinnings for each GBL intervention: (a) impacts of oversteer versus understeer [50]; (b) primary tire parameters associated with vehicle sideslip [51]; (c) stable (green) versus unstable (red) braking trajectory scenarios, resulting from the yaw moment [52].

\section{Results and Discussion}

In this section, we present the preliminary results from each of our three GBL interventions. Our participant cohort consisted of college engineering students (i.e., senior undergraduates, and graduate students) who were enrolled in a technical elective (400/500-level) engineering course entitled Road Vehicle Dynamics (RVD) which covers ground vehicle dynamics, including the basics of automobile motion, stability, and control. Although cohort demographics are not formally tabulated here, students in the course (typical participant age: $23-25$ years; typical driving experience: $3-5$ years) consented to participation in the experiments as a portion of their course experience, and these experiments were preapproved through the University at Buffalo's Institutional Review Board (IRB). Data that was collected is entirely quantitative (i.e., as measured by the simulator) in nature, as appropriate for the specific nature of each experimental implementation. As a primary component of our discussion, we outline the broader impacts of our findings with relation to safety (i.e., related to both drivers/occupants, and vehicle). Our results were tabulated, analyzed, and reported using Microsoft Excel.

\subsection{Skid Pad Intervention}

For the skid pad intervention, a total of $n=44$ student drivers participated. For the sake of deployment logistics, four sub-cohorts (each having 11 drivers) were tasked with the identical exercise of modifying their vehicle's CG toward a desirable neutral steer configuration; this state would implicitly enable the completion of as many laps as possible on a tight circular track (within a two-minute experiment window). Each vehicle was 
initially configured as "oversteer" with the CG intentionally shifted so far aft that the car was undrivable at all but low speeds. Typically, an oversteer vehicle will tend to rotate (yaw) nose-in at elevated speeds of greater than approximately $30 \mathrm{mph}$. Naturally, this unstable vehicle state encouraged trainees to interactively use steering wheel paddle shifters to adjust their CG forward and thus immediately counteract the instability. However, shifting the CG too far forward modified the car to an "understeer" configuration, less sensitive to steering commands, and therefore unable to maintain the specified radius at elevated (optimized) speeds. In such an instance, overadjustment of the CG forced students to subsequently either reduce their travel speed (and suffer slower lap times), or re-modify the CG toward an optimized "neutral steer" balance point to achieve and maintain a speed that is optimal for that vehicle.

Figure 14 represents a cumulative plot (decomposed per sub-cohort), and records how the four student cohorts adjusted the CG of their vehicle as a function of time, depicting the ratio of front cornering stiffness to front weight distribution. As this ratio approaches unity, the vehicle approaches its ideal "neutral steer" condition. Therefore, on average, all four sub-cohorts successfully modified the vehicle CG toward neutral steer in an exponential fashion. Overall, this observation suggests that trainees consistently engaged with the effect of the CG on the vehicle dynamics throughout the training exercise. From the plot, we observed that most students made large adjustments early within the allotted experimental timeframe to counteract what were obvious (initial) vehicle performance deficiencies. Then, as sub-cohort students increased speed and gained confidence, they continued to make more precise compensations to fine-tune and experientially converge upon more subtle performance gains. It is likely that the observed effectiveness of student conceptual understanding was directly enabled by experiential (hands-on) GBL. In other words, through active learning, this intervention provided a unique mechanism for novice learners to practice inductive reasoning [53] —imparting broader educational impacts on critical aspects of vehicle operation, performance, and safety—all of which would likely have been far less effective (and memorable) if conventional passive classroom instruction had been relied upon exclusively.

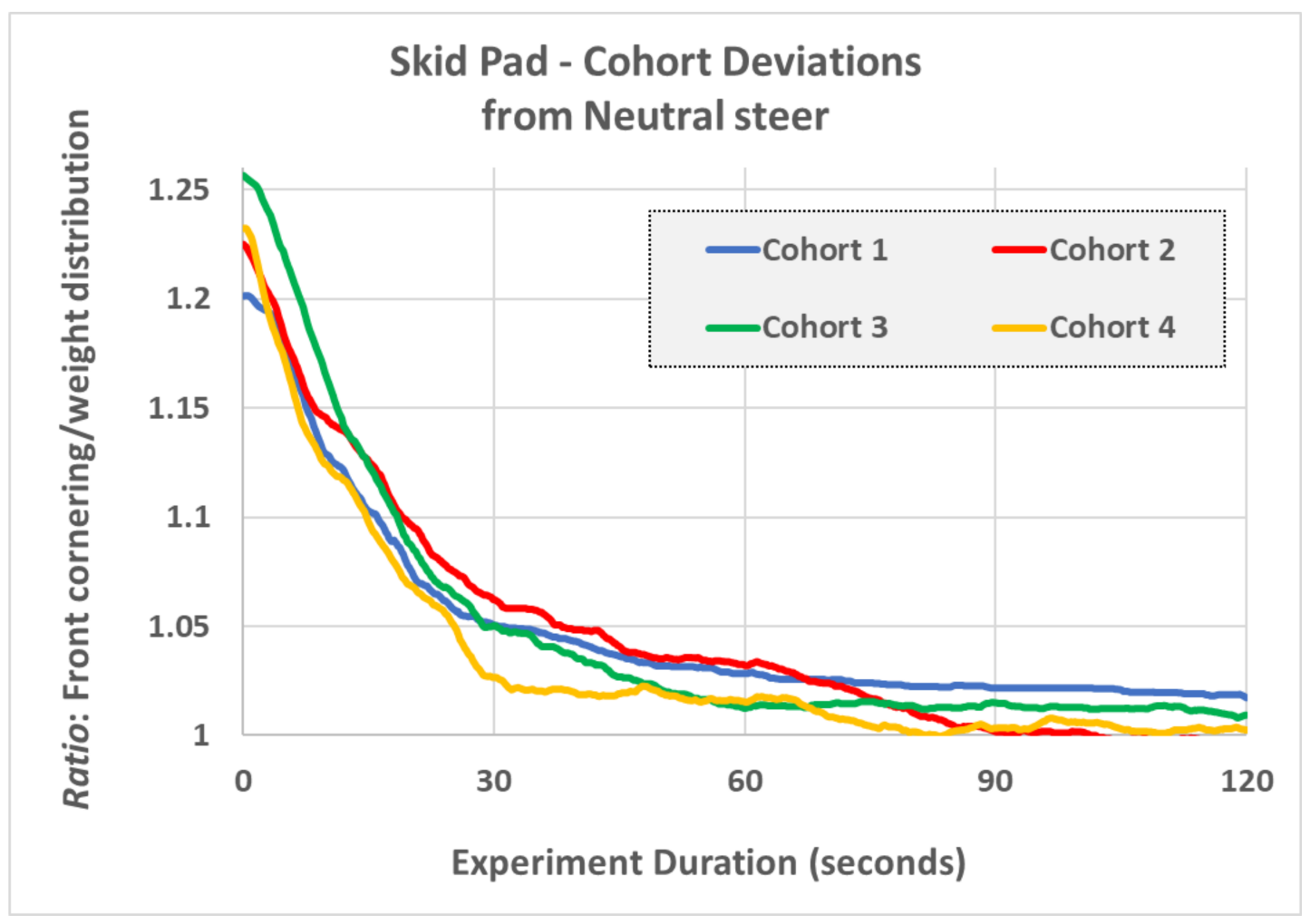

Figure 14. Skid pad cohort deviations from neutral steer. 


\subsection{Triple Curve Intervention}

For the Triple Curve intervention, a total of $n=48$ student drivers participated; 24 each allocated to the gauge/ghost trainer sub-cohorts. To assess quantitative differences in vehicle cornering performance, and experimental outcomes between the ghost trainer and gauge trainer cohorts, we first compare the racing trajectories of each group to an ideal trajectory generated by a small cohort of "expert" drivers. These results are displayed for each sub-cohort (expert/gauge/ghost) using a (green/red/blue) color-coding scheme, respectively. Figure 15 compares results for all three cohorts that relate primarily to laps and errors. As illustrated in the plot, total laps (attempted) were comparable across cohorts, but both student (gauge/ghost) cohort averages were higher than that achieved by the expert driver. Likewise, overall distance travelled (in miles) was comparable across cohorts. Most compelling about this figure are the remaining two series: notably, the expert driver achieved more legal laps than either of the (averaged) student cohorts, with the ghost cohort slightly outperforming the gauge cohort. Similarly, the expert driver drove without any cumulative errors (e.g., which included cone nicks/minor; tree strikes/moderate; and vehicle spinouts/major); while both student cohorts demonstrated errors during their drives, with the ghost cohort demonstrating a slightly higher number. The primary takeaways from this chart are that the expert driver demonstrated a consistent and conservative approach towards the primary training goal (\# legal laps); the students were more aggressive and less effective at achieving this goal, with the ghost cohort performing better overall (than gauge), but with a "risk vs. reward" aggression that resulted in a higher likelihood for critical driving mistakes. Figure 16 offers companion results for the same cohorts (primarily relating to speed), with all three series reporting as comparable. As shown, the fastest laps for all three cohorts were approximately $24.0 \mathrm{~s}$, average speeds were in the vicinity of $63.0 \mathrm{mph}$, and maximum speeds (achieved in the straightaway sections) were recorded to be just over $80.0 \mathrm{mph}$.

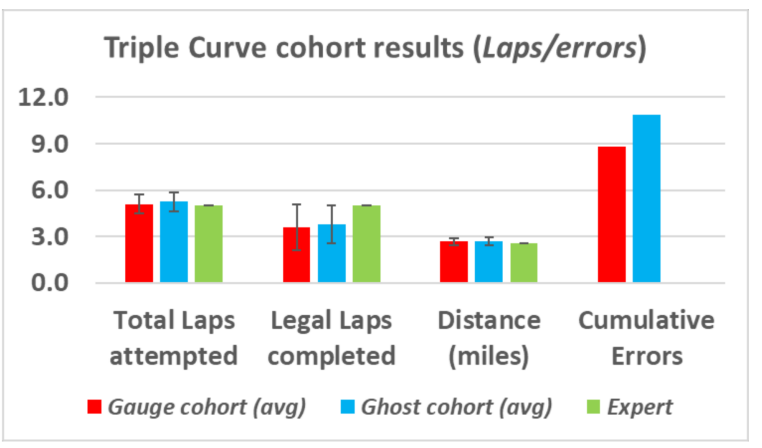

Figure 15. Triple Curve (laps/errors).

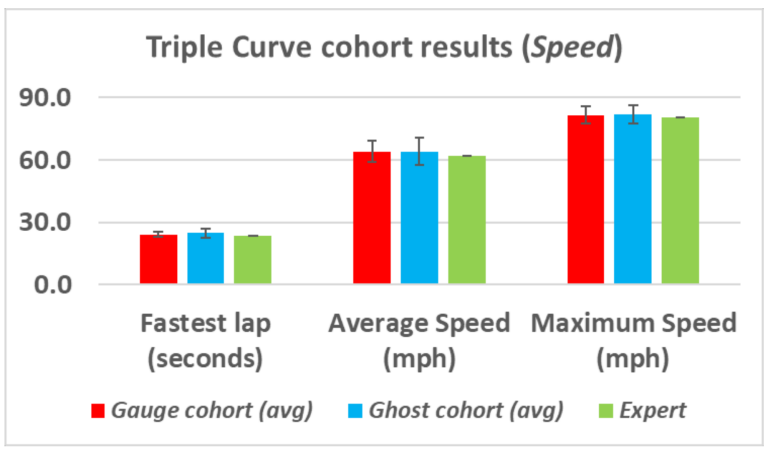

Figure 16. Triple Curve (speed).

Figure 17 continues the Triple Curve analysis by comparing the racing trajectories of student (gauge/ghost) cohorts to that of the expert driver, and implements the same 
color scheme. For the expert driver, a single trajectory is shown; for the student cohorts, the cohort-averaged upper/lower bounds are depicted to illustrate the respective ranges of data collected. The expert driver (green) tends to hold an outside lane position in the straight sections, brakes into a tight radius through the apex of each corner, and then transitions again strategically to an outside lane position. The ghost trainer (blue) and gauge trainer (red) cohorts share similar characteristics to the expert driver, however the key difference observed is the variability of driver behavior at the exit of each corner, as indicated by the widening of the cumulative cohort drive paths (i.e., upper/lower bounds). This is indicative of novice trainees (from both student cohorts) reaching the tire saturation limits and subsequently losing control at the later stages of each corner. This behavior is observed to be more pronounced with the ghost trainer cohort (blue), whose bounds completely engulf the gauge trainer bounds.

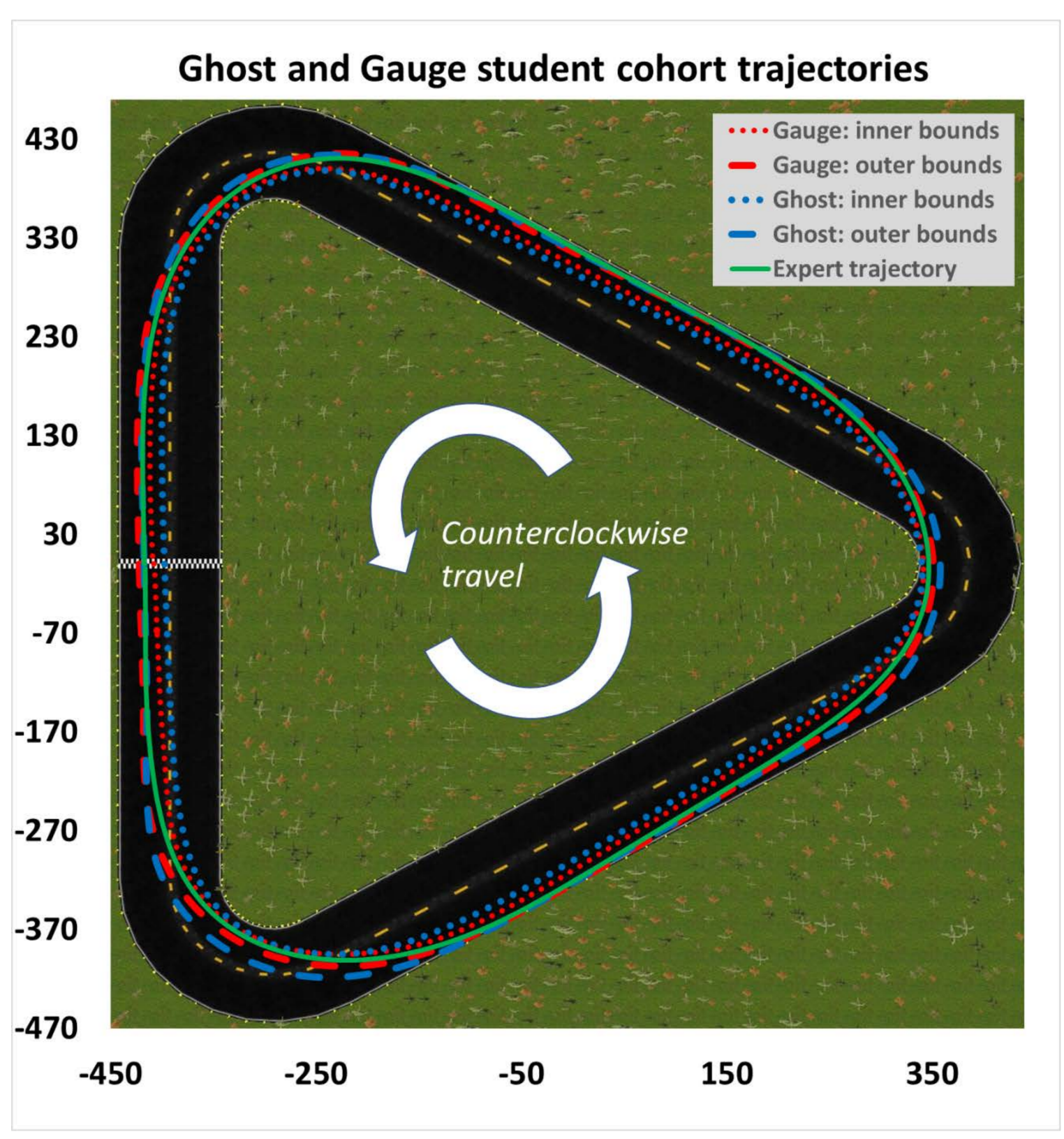

Figure 17. Ghost trainer vs. gauge trainer race trajectories (with upper/lower bounds).

Detailed cohort performance behavior is dissected in greater detail with a $\mathrm{G}-\mathrm{G}$ diagram [54] (Figure 18)—a traditional graphical mechanism for assessment of cornering 
performance by displaying longitudinal acceleration (i.e., throttling/braking forces) as a function of lateral acceleration (i.e., centripetal forces). Both series are plotted in units of G-force (i.e., the acceleration of gravity, which is $32.2 \mathrm{ft} / \mathrm{s}^{2}$ ), hence the name of the diagram. Ultimately, the diagram is instituted to verify that the driver is operating the vehicle to its full potential. As observed, the expert driver (green) enters the corner with controlled aggression, and then, smoothly, reduces braking force to approximately $-0.22 \mathrm{~g}$ 's of lateral acceleration, as the longitudinal acceleration obtains a corresponding maximum of $-1.8 \mathrm{~g}$ 's Subsequently, the brakes are gradually released and the throttle is introduced as the lateral acceleration works back toward zero, and the vehicle begins to straighten out. Notice that both the gauge trainer and ghost trainer cohorts employ considerably less deceleration going into the corner than the expert driver. The lateral acceleration for the ghost trainer cohort reaches a minimum of $-0.17 \mathrm{~g}$ 's, and the gauge trainer cohort brakes even less, with a maximum of approximately $-0.1 \mathrm{~g}$ 's. Because both cohorts, on average, brake too little and too late into each corner, they enter the apex with too much speed. As a result, a peak longitudinal acceleration in excess of a safe $-1.8 \mathrm{~g}$ 's is observed, and this pushes the front tires beyond their saturating slip angles. This means that the vehicle cannot turn any further (i.e., given its current speed and heading angle) with continued and increased attempts at steering.

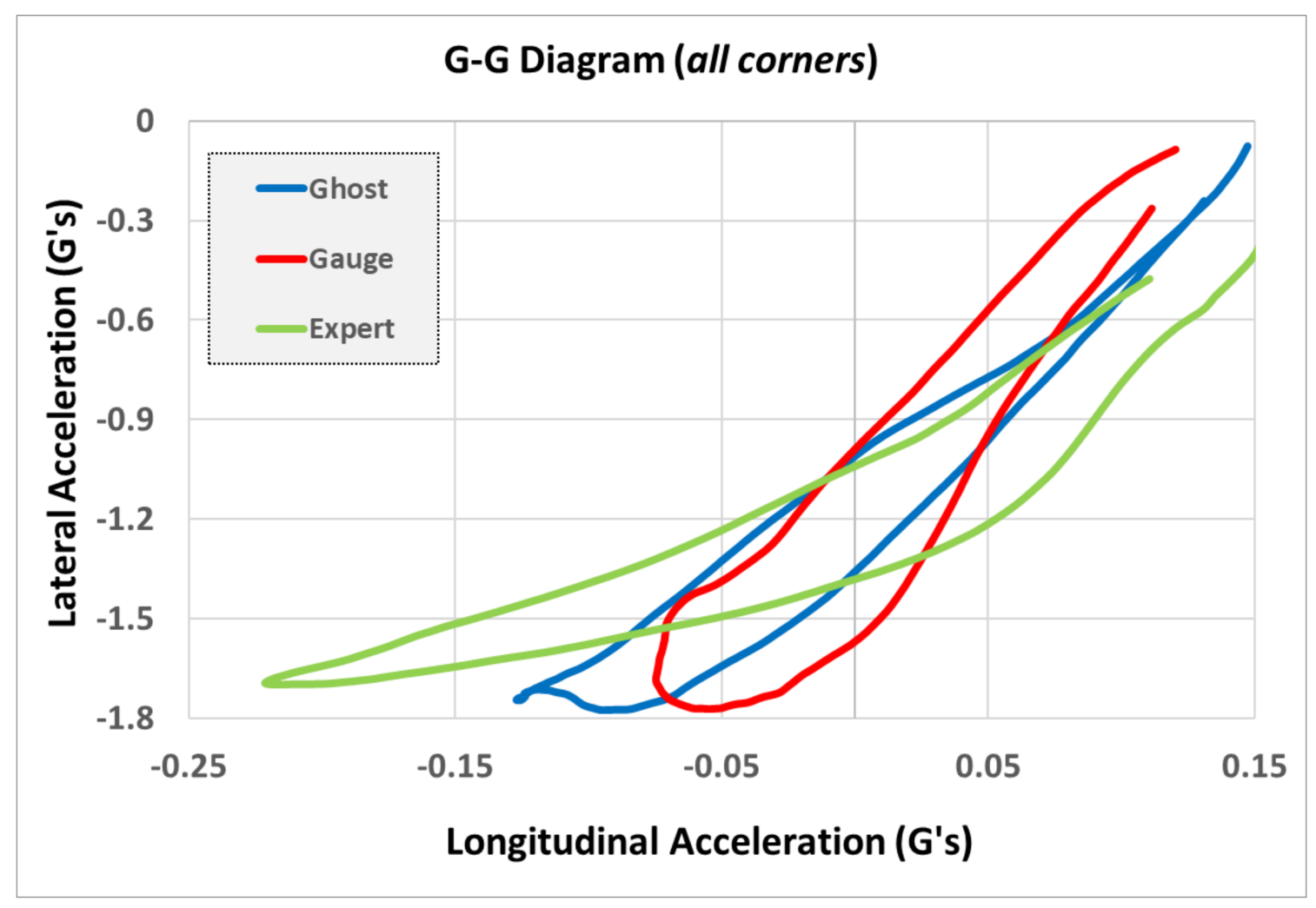

Figure 18. Ghost vs. gauge G-G diagram (averaged across all cornering).

In Figure 18, it is also clear that the contour of the acceleration profile for the ghost cohort spans a greater range than that observed for the gauge cohort, indicating larger magnitudes of accelerations-and more aggressive cornering. The greater uniformity of performance across the gauge cohort can likely be attributed to the more systematic GBL training elements that were provided to those drivers: a visible (suggested) racing line, brake/throttle cues, and a tire slip angle heads-up contour display. While the ghost trainer cohort could deduce a racing line by following the ghost vehicle on the track, this friendly competitor vehicle outpaced most drivers, and quickly left their immediate field of view. Additionally, the implied incentive to "race" the ghost vehicle likely encouraged a more aggressive racing strategy beyond their simulated driving capabilities (and one 
that is unsafe for novice drivers), resulting in the larger overall variation in observed performance behavior.

\subsection{Moose Test Intervention}

For the Moose Test intervention, a total of $n=24$ student drivers participated. To quantify simulator performance in navigating the Moose Test courses, each driver's deviation from an ideal path was calculated, as depicted in Figure 19.

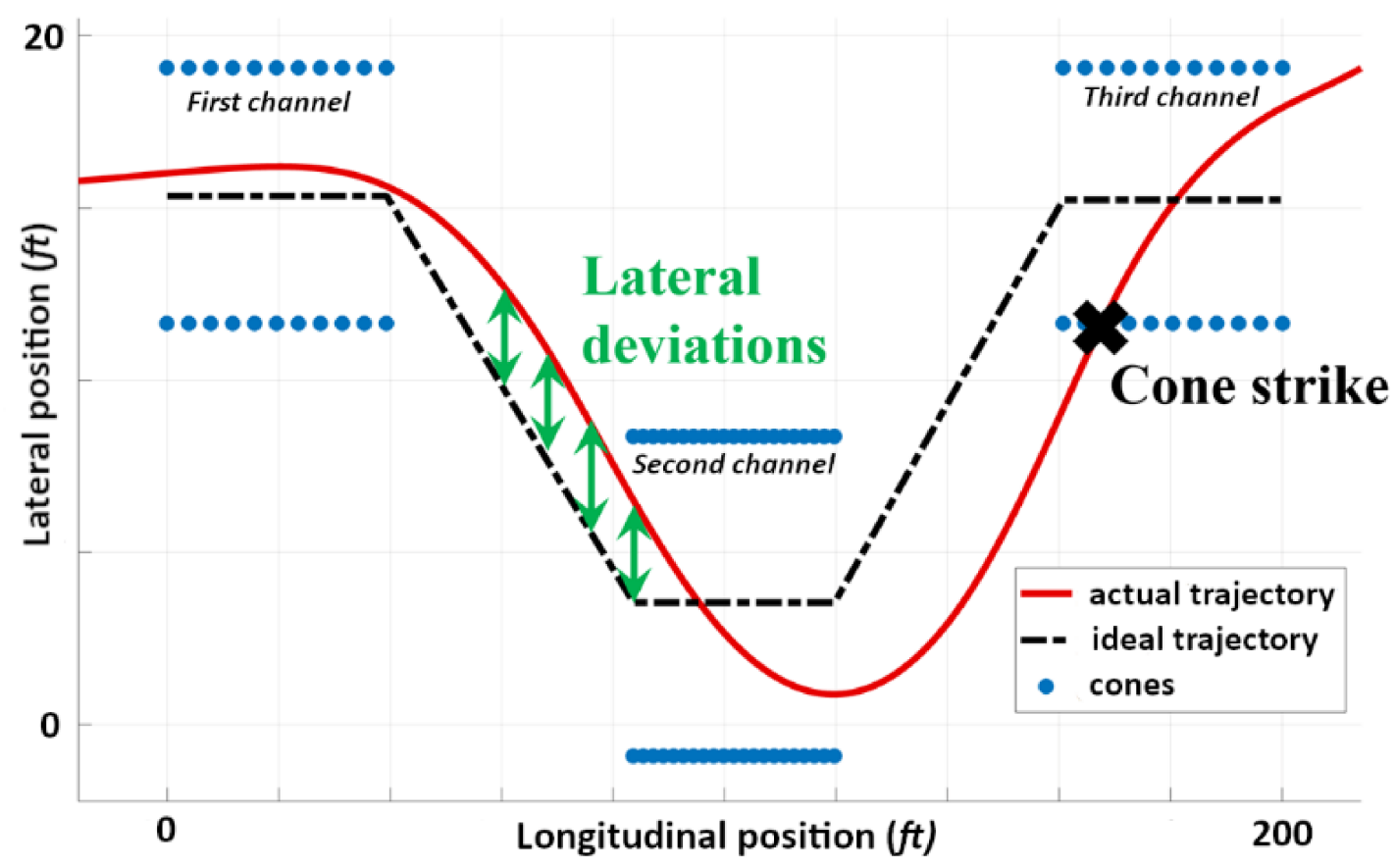

Figure 19. Lateral deviations as a metric for quantifying Moose Test performance.

Along the length of each course, the squared lateral deviation from the ideal trajectory was calculated and summed to provide a cumulative score (i.e., with a zero-score being optimal). Thus, the simulator score, $J$, is defined by a simple mathematical model defined in Equation (2).

$$
J=\sum_{i=1}^{P}\left(y_{i}-y_{i}^{*}\right)^{2} \Delta x
$$

Here, $y_{i}$ is the lateral position of the vehicle, $y_{i}{ }^{*}$ is the ideal lateral position, and $\Delta x$ is the longitudinal discretization interval for the course (summed across a total of $P$ intervals), implemented for normalization. Each driver navigated both the original and modified Moose Test courses at entry speeds of 20,30, and $40 \mathrm{mph}$; with and without (yaw stabilization) electronic speed control (ESC). To demonstrate the scoring procedure, Figure 20 offers sample representative data, at all three entry speeds, for the modified Moose Test course.

To evaluate the effect of electronic speed control (ESC) on each driver, at each entry speed, we calculated percent improvement in score (with assisted control). Table 4 presents average cohort scores for both the original and modified Moose Tests, at all three entry

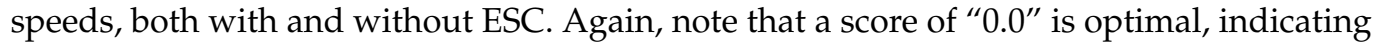
null deviation (per unit time) from the ideal trajectory through each course. From this table, as expected, we observe a general upward trend in score with entry speed. However, note that for the original Moose Test, scores tended to decline from 20 to $30 \mathrm{mph}$ (i.e., likely due to insufficient cohort size), before dramatically increasing for the 40-mph experiment. In addition, note that scores generally increased (improved) with the presence of the ESC, but 
that tendency tended to have a strong correlation with driver skill (as is discussed shortly), and the severity of improvement varied with entry speed.

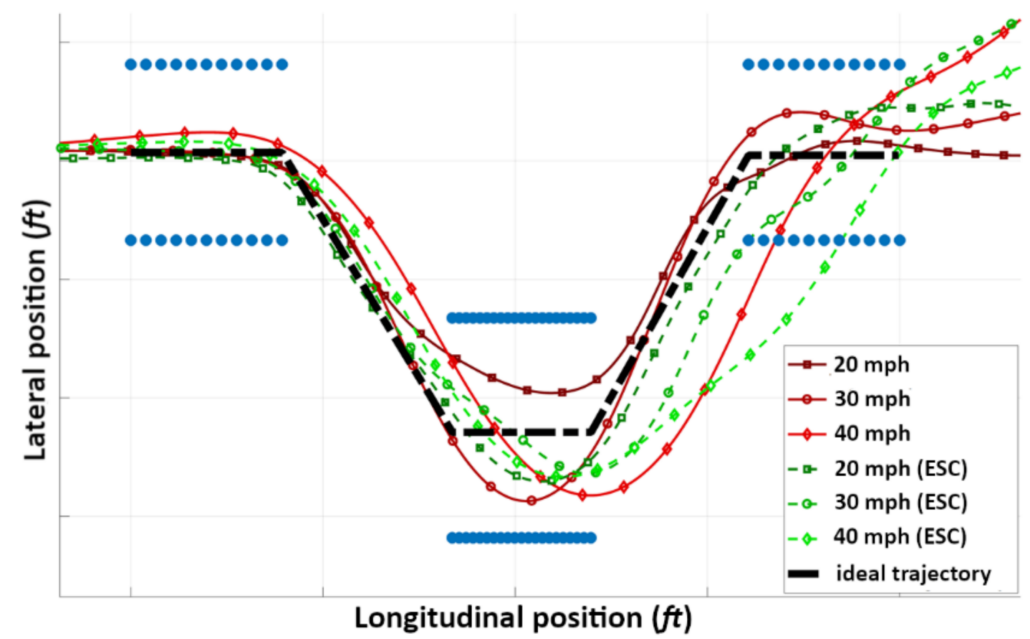

Figure 20. Simulator trial (sample data) for the modified Moose Test.

Table 4. Cohort average simulator score summary (lower scores indicate better performance).

\begin{tabular}{lccc}
\hline & $\mathbf{2 0 ~} \mathbf{~ p h}$ & $\mathbf{3 0 ~} \mathbf{~ p h}$ & $\mathbf{4 0 ~} \mathbf{~ p h}$ \\
\hline Original (no ESC) & 4364 & 2899 & 8037 \\
Original (with ESC) & 1627 & 886 & 2046 \\
Modified (no ESC) & 671 & 2607 & 8016 \\
Modified (with ESC) & 367 & 1403 & 2982 \\
Original (no ESC) & 4364 & 2899 & 8037 \\
Original (with ESC) & 1627 & 886 & 2046 \\
Modified (no ESC) & 671 & 2607 & 8016 \\
Modified (with ESC) & 367 & 1403 & 2982 \\
\hline
\end{tabular}

Figures 21 and 22 depict improvement as a function of speed for the original/modified courses. The horizontal axis reports the simulator score obtained without the presence of ESC, which ranges from 0.0 on the far left (i.e., a perfect driving rating), to 50,000 on the far right (i.e., a highly-flawed driving rating); note that this axis is plotted not linearly, but logarithmically. The simulator score without ESC can be considered a measure of the driver's natural (simulator) driving ability. Therefore, data points farther to the left are indicative of drivers with higher skill. The vertical axis depicts percent improvement with the presence of the ESC, ranging from $-500 \%$ (i.e., indicative that driver scores declined with the presence of the ESC) up to $100 \%$ (i.e., the threshold which would indicate dramatic improvement with the presence of the ESC). Note that the vertical axis is presented on a linear scale. For the lower speeds evaluated in our experiment (i.e., 20 and $30 \mathrm{mph}$ ), drivers with a better (lower) unassisted score were observed to perform worse with the assistance of ESC. This trend is indicated by the red and blue markers (for both original and modified Moose Tests) demarcated predominantly on the lower portion of the plot, below the $0 \%$ line on the $Y$-axis, and towards the left-hand side of the chart. However-those with inferior (higher) scores without ESC improved significantly with assisted (ESC) control. These drivers are demarcated by the red/blue markers towards the top-right corner of the charts (for both original and modified Moose Tests). Not surprisingly, at $40 \mathrm{mph}$ (i.e., the green markers, on both charts), almost all drivers clearly benefited from the assisted control (ESC). This is demarcated by the markers appearing, almost predominantly, across the top band on the chart (above the $0 \%$ axis line). 


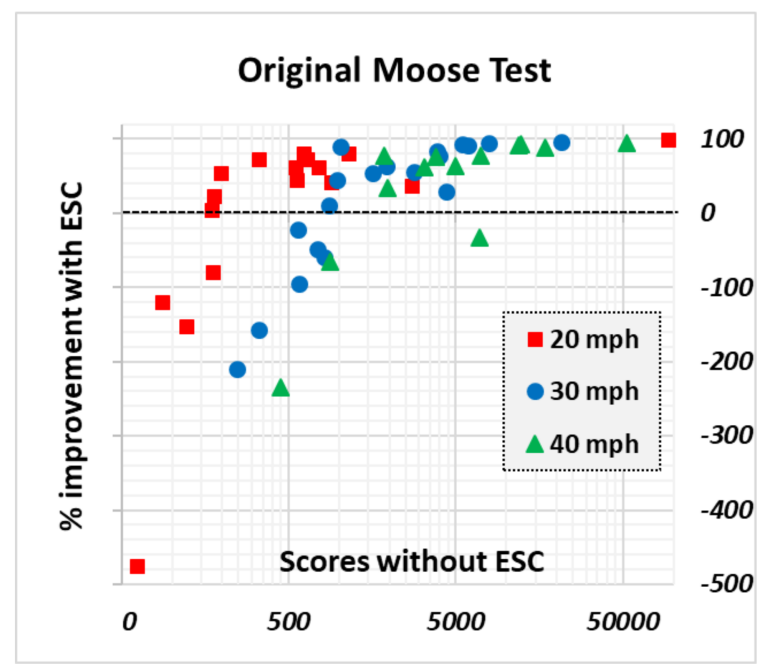

Figure 21. Percent improvement with electronic stability controller (ESC). (original Moose Test).

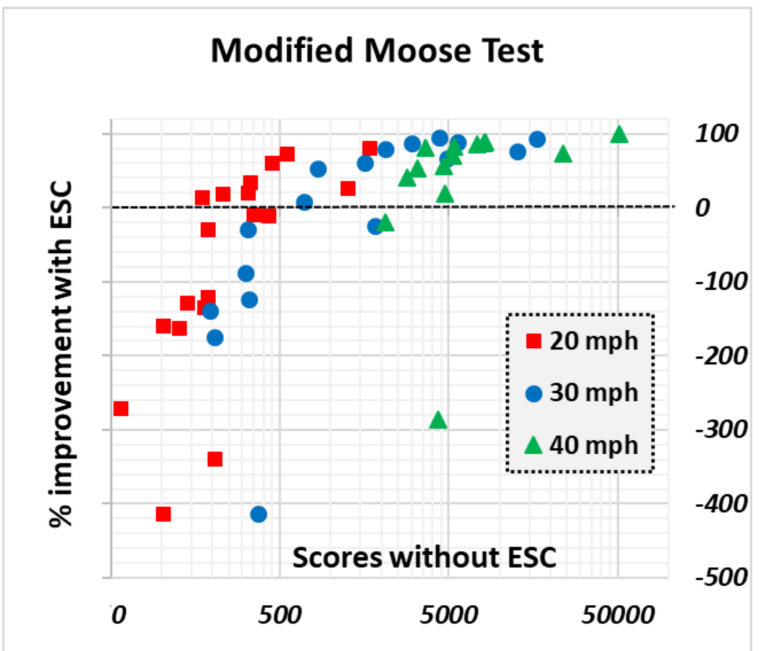

Figure 22. Percent improvement with ESC (modified Moose Test).

Finally, the average full-circuit trajectories for the drivers were calculated for the original and modified Moose Tests (shown as data series), along with the \pm 1 standard deviation bounds (shown as shaded regions using the same series color). Data for the modified tests are plotted in Figure 23, as observed trends were similar for both variations of the ISO 3888-2. Note that the trajectories without the ESC controller are shown in red, while the controller-assisted (ESC) trajectories are shown in green. As observed within the sequence of figures, on average, drivers successfully exit the first channel of cones (shown in blue) and enter the second channel without incident. This tendency is indicated by the smooth green lines (and the very narrow red band) on the leftmost sides of the plots. However, upon entering the second channel of cones, drivers tend to overshoot the lane center. This effect is amplified with increasing speed, where the magnitude of the overshoot increases, and the peak of the overshoot is pushed further down the course. This tendency (i.e., the moderate red error bands widening, and the effect amplified with increasing speed) can be viewed, in all three charts, in the bottom-middle segment of the plots. To compensate for this overshoot, drivers subsequently had a tendency to make a dramatic steering adjustment while exiting the second channel of cones, leading to an even greater overshoot when entering the third channel—and with greater delay. Thus, in general, the steering commands were too dramatic and were tendered too late. At $20 \mathrm{mph}$, many drivers were able to manage their error relatively unscathed; at $30 \mathrm{mph}$, and especially at $40 \mathrm{mph}$, almost all drivers were consistently observed to strike either the 
inner or outer cone boundary of the third cone channel. This tendency (i.e., very wide red bands, greatly amplified with increasing speed) can be seen on the rightmost side of the chart sequence.

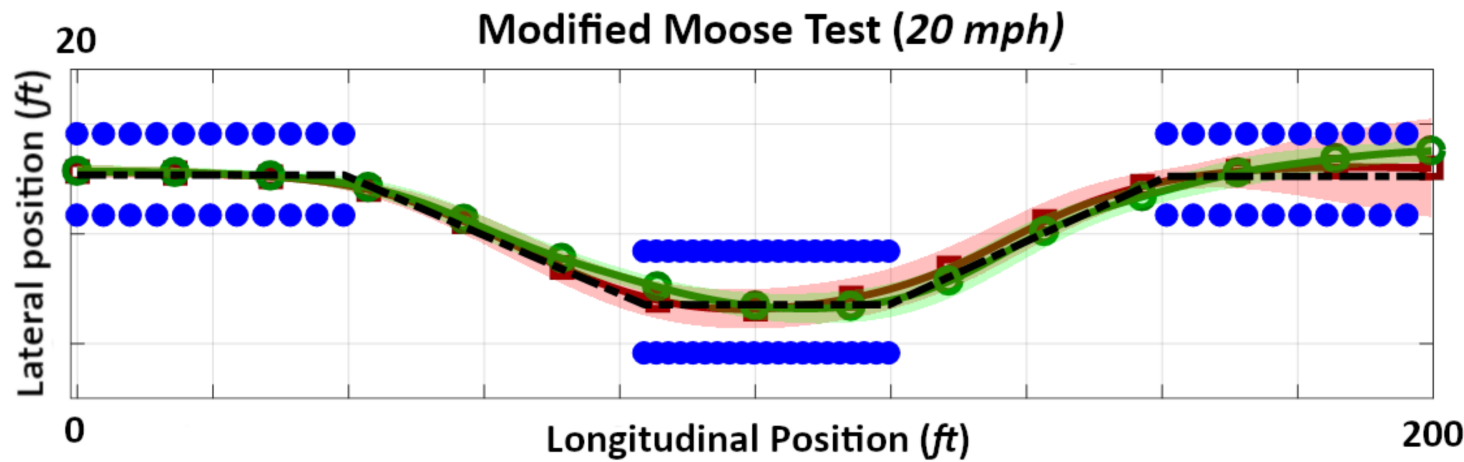

(a)

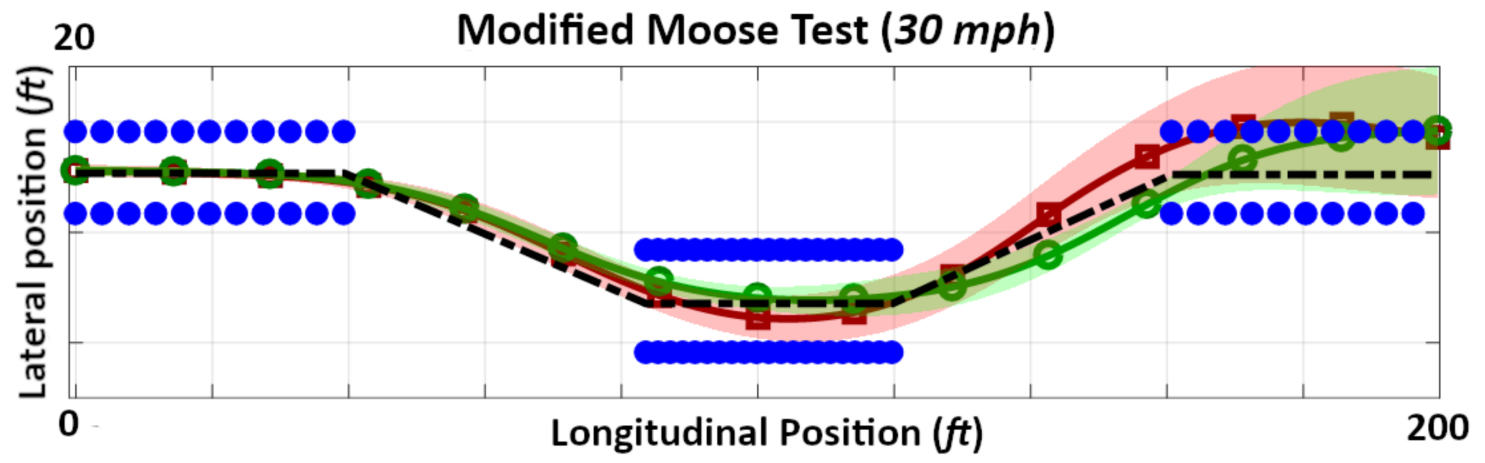

(b)

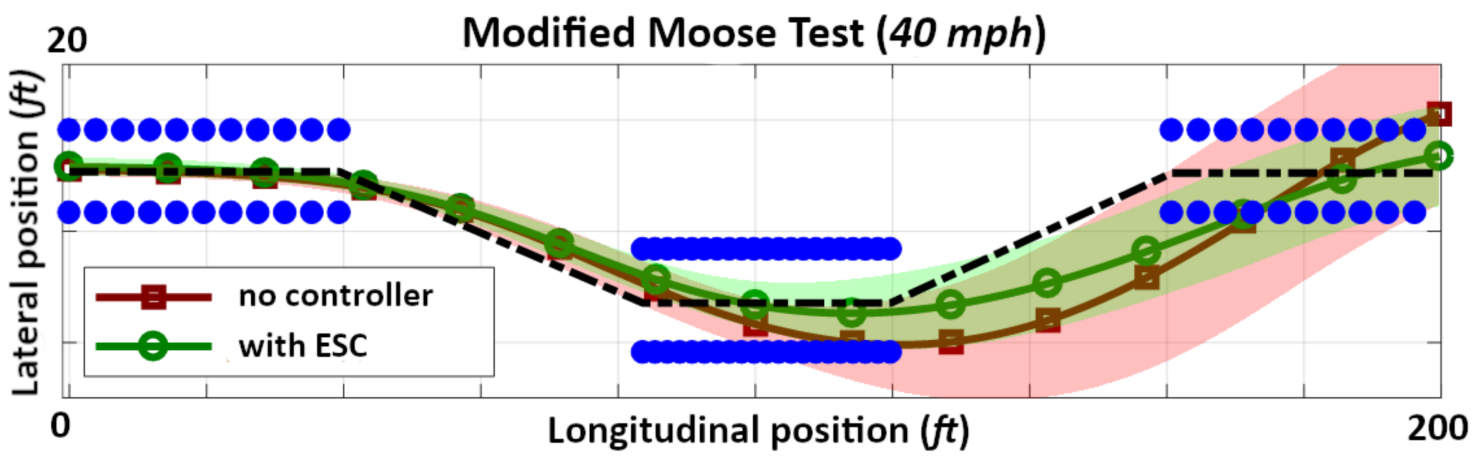

(c)

Figure 23. Modified Moose Test per cohort average trajectories at different entry speeds: (a) $20 \mathrm{mph}$, (b) $30 \mathrm{mph}$, and (c) $40 \mathrm{mph}$.

Comparing the trajectories with and without ESC, the control-assisted trajectories remain closer to the ideal path over the range of tested speeds, and with tighter variance (i.e., smaller standard deviation). The ESC attenuates lane overshoots, and damps lateral motion of the vehicle, helping drivers align the vehicle before exiting the second channel of cones. However, while the ESC, on average, improves performance on the original and modified moose maneuvers, we found that drivers with the highest unassisted simulator scores (i.e., those that were better natural simulator drivers) had a tendency to be detrimentally impacted by stability control. This general trend was observed at low and moderate speeds; however, at $40 \mathrm{mph}$ (i.e., the highest entry speed examined), the ESC feature proved to be universally beneficial. 


\section{Conclusions and Future Work}

Within the discipline of transportation engineering, a vastly improved comprehension of how a vehicle functions can be achieved with advanced educational tools to supplement conventional (passive) instructional techniques. In this paper, we presented a novel research methodology that builds upon previous research in game-based learning (GBL) by demonstrating hands-on, experiential interventions intended to better educate young engineers and substantially improve conceptual understanding of vehicle dynamics. In companion with these interventions, we employed gamification techniques to engage and motivate cohort trainees to comply with the goals of the interventions towards achievement of the intended training objective. Our implementation should promote similar instructional methodologies that result in positive downstream impacts on safety, both for the vehicles (e.g., controls, designs, interfaces), and drivers and operators of tomorrow's automotive technologies.

With our Skid Pad intervention, our goal was to enhance understanding of oversteer/understeer vehicles at ever-increasing speed. Through our GBL implementation, students successfully modified the vehicle CG toward neutral steer exponentially, and consistently engaged with the effect of the CG on the vehicle dynamics throughout the training exercise. Student conceptual understanding was enabled by experiential (handson) GBL and provided a unique mechanism for students to practice inductive reasoning in a manner that would likely have been far less effective through passive instruction alone. With our Triple Curve intervention, our goal was to enhance understanding of optimal cornering strategies subject to the tire conditions of the vehicle. Overall, when compared to the expert driver-the students were more aggressive and less consistent at achieving the primary training goal (i.e., legal laps per unit time), with the ghost cohort outperforming the gauge cohort, but with a "risk vs. reward" aggression that resulted in a higher likelihood for critical driving mistakes. This general tendency resulted in a greater observed uniformity of training performance across the gauge cohort than the ghost cohort, likely attributed to the explicit GBL training elements that were provided to the gauge drivers, as opposed to those that had to instead be deduced by the ghost drivers. Finally, with the Moose Test intervention, our goal was to enhance understanding of lateral handling and yaw stabilization of a vehicle within an extreme evasive roadway maneuver. At lower entry speeds, drivers who demonstrated natural proficiency in navigating the Moose Test maneuver performed worse with the presence of ESC. Rather, those among the cohort who drove poorly during conditions without the aid of a controller tended to improve significantly with the presence of ESC. Noteworthy also is that at elevated speeds, almost all drivers benefited from assisted yaw stability control. This observation suggests that every driver likely has a transition (speed) threshold where electronic driver assistance is beneficial.

\subsection{Constraints and Limitations of Current Implementation}

As with any novel and cutting-edge training implementation, it is important to recognize the inherent constraints and limitations of the GBL implementation towards broader application. Despite many advantages, simulator-based training also has some noteworthy drawbacks. For some trainees, it is difficult to overcome the perception that a simulator is an imitation of reality. This inherent absence of truly "being there" can result in negative training [55], and acquired skills might not be appropriately applied to real-world application. Another primary concern is "simulator sickness" [56], a sensory conflict that can manifest itself through sweating, dizziness, headaches, nausea, and other maladaptive symptoms. Fortunately, past studies have demonstrated that simulator sickness is less frequent with younger individuals [57], who were predominant in the cohorts studies here. Finally, it should be understood that historically, games are not automatically effective in educational settings. To be successful, they must be rooted in effective pedagogical practices. In other words, the implementation of "surface characteristics" of gamification (e.g., badges and rewards), without employing rigorous game design elements, can actu- 
ally inhibit (rather than enhance) student engagement [58]. Under optimal circumstances, games, however, have long served as a convenient medium for creating a training domain whereby students can safely and successfully interact with authentic problems with real-world implications.

\subsection{Future Pathways}

The research described in this paper serves as a proof-of-concept for systematically employing GBL to observe human behavior in varied driving situations and vehicle conditions. Within transportation engineering, such analyses could enable a greater understanding of the human-machine interface to provide much-needed insights on human tendencies and behaviors related to next-generation vehicle technologies. As an example, input shaping [59] is a pure feed-forward, "open loop" control technique to minimize unwanted residual responses (i.e., vehicle state outputs) to a prescribed input (e.g., a steering command). Using real-time driving and advanced simulation, deployment of input shaping could be successfully demonstrated and subsequently implemented to improve human factors and human-vehicle machine interfaces that will enhance vehicle design safety and driver control of next-generation connected and automated vehicles.

The research methodology and preliminary findings presented here are intended to demonstrate a foundation to revolutionize the form/function of content delivery within future engineering education. Our broader strategic vision is to conceive, develop, and deploy a wider series of GBL courseware, leveraging advanced modeling and simulation $(M \& S)$ and emergent gamification approaches to improve learner engagement, training effectiveness, and, ultimately, long-term success rates for vocational preparation. Largely through the direct influence of our present efforts, in development is a revised engineering education taxonomy (courseware and assessment standards) that will rigorously incorporate game design characteristics that have been consistently associated with positive learning outcomes [60].

Refer to Figure 24, which illustrates the primary (notional) components of our proposed logic model (i.e., a "Theory of Change") for authentication of GBL in engineering education on a much broader scale. This strategic vision will be achieved through the implementation of extensible instructional components and methodological principles that will more effectively engage critical thought processes for solving "real-world" problems. The proposed model is explicitly designed to build specific skills in engaging GBL activities and metacognitive competence - to increase active learner participation, and promote positive engagement with instructional materials. We hypothesize that through the execution of these model elements, we will enable an optimal atmosphere to improve short-term and long-term learning outcomes, including safety standards within all sub-disciplines of engineering design.

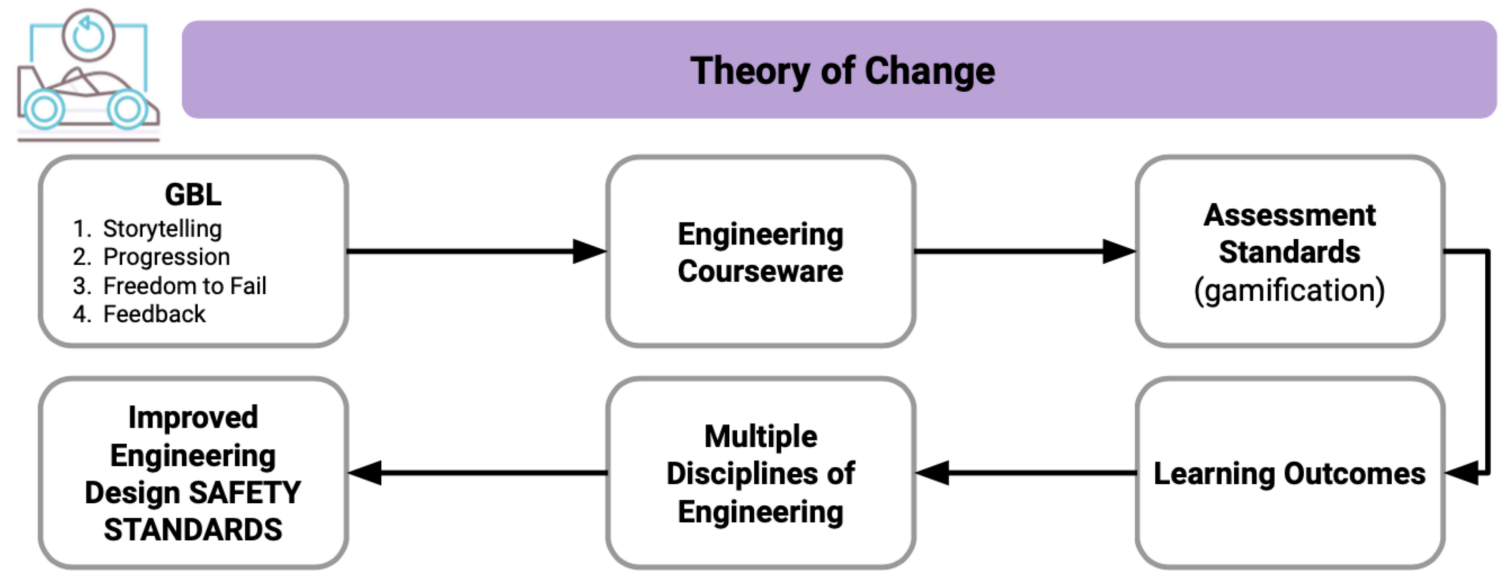

Figure 24. A Theory of Change in engineering education to enhance design and safety. 
Author Contributions: Conceptualization, M.S. (Matthias Schmid), A.E., and K.F.H.; methodology, A.E., M.S. (Matthias Schmid), and K.F.H.; software, K.F.H., A.E., and M.S. (Matthias Schmid); validation, K.F.H., A.E., M.S. (Matthias Schmid), R.S.A.L., and M.S. (Mark Schiferle); formal analysis, M.S. (Mark Schiferle), R.S.A.L., A.E., and K.F.H.; investigation, A.E., M.S. (Matthias Schmid), K.F.H., R.S.A.L., and M.S. (Mark Schiferle); data curation, R.S.A.L., M.S. (Mark Schiferle), A.E., and K.F.H.; writing — original draft preparation, K.F.H., R.S.A.L., A.E., and M.S. (Mark Schiferle); writingreview and editing, R.S.A.L., K.F.H., and A.E.; visualization, K.F.H. and R.S.A.L.; supervision, K.F.H., A.E., and M.S. (Matthias Schmid); project administration, K.F.H., A.E., and M.S. (Matthias Schmid); funding acquisition, K.F.H. and A.E. All authors have read and agreed to the published version of the manuscript.

Funding: While this research received no direct external funding, the authors wish to gratefully acknowledge original funding support from the National Science Foundation's Course, Curriculum, and Laboratory Improvement (CCLI) program (NSF award\# 0633596; PI Kemper E. Lewis)—which served as the original impetus and motivation for this work.

Institutional Review Board Statement: The study was conducted according to the guidelines of the Declaration of Helsinki, and approved by the Institutional Review Board of the University at Buffalo Internal Review Board (protocol code 030-STUDY00002749 on 16 August 2018).

Informed Consent Statement: Informed consent was obtained from all subjects involved in the study.

Data Availability Statement: The data presented in this study are available on request from the corresponding author. The data are not publicly available due to participant privacy and confidentiality concerns related to the terms of the study IRB.

Acknowledgments: The authors are grateful for the ongoing support from the Mechanical and Aerospace Engineering Department at the University at Buffalo (UB). In addition, the authors wish to gratefully acknowledge the financial and technical support provided by Moog, Inc. (East, Aurora, NY, USA) whose key contributions have enabled physics-based modeling and real-time motion simulation to improve experiential learning, dynamics education, and driver safety at UB. The authors wish to thank Lisa Zimmerman for her assistance in preparing this manuscript. Lastly, authors Hulme and Lim are grateful for the ongoing support of the UB Stephen Still Institute for Sustainable Transportation and Logistics (SSISTL).

Conflicts of Interest: The authors declare no conflict of interest.

\section{References}

1. National Highway Transportation Safety Association (NHTSA). Traffic Safety Facts—2013 Data; National Highway Traffic Safety Administration: Washington, DC, USA, 2015.

2. Centers for Disease Control and Prevention (CDC); National Center for Injury Prevention and Control. Web-Based Injury Statistics Query and Reporting System (WISQARS) Fatal Injury Data; CDC: Atlanta, GA, USA, 2017.

3. National Highway Transportation Safety Association (NHTSA). National Motor Vehicle Crash Causation Survey-Report to Congress; National Technical Information Service: Springfield, VA, USA, 2008.

4. Smith, B.W. Human Error as a Cause of Vehicle Crashes, the Center for Internet and Society (CIS). 2013. Available online: http:/ / cyberlaw.stanford.edu/blog/2013/12/human-error-cause-vehicle-crashes (accessed on 14 November 2020).

5. Sokolowski, J.A.; Banks, C.M. (Eds.) Principles of Modeling and Simulation: A Multidisciplinary Approach. 2009. Available online: https:/ / digitalcommons.odu.edu/vmasc_books/2 (accessed on 14 November 2020).

6. National Research Council (NRC). 9. Using Modeling and Simulation in Test Design and Evaluation. In Statistics, Testing, and Defense Acquisition: New Approaches and Methodological Improvements; The National Academies Press: Washington, DC, USA, 1998.

7. Feisel, L.D.; Rosa, A.J. The Role of the Laboratory in Undergraduate Engineering Education. J. Eng. Educ. 2005, 94, 121-130. [CrossRef]

8. Potkonjak, V.; Gardner, M.; Callaghan, V.; Mattila, P.; Guetl, C.; Petrović, V.M.; Jovanović, K. Virtual laboratories for education in science, technology, and engineering: A review. Comput. Educ. 2016, 95, 309-327. [CrossRef]

9. Amirkhani, S.; Nahvi, A. Design and implementation of an interactive virtual control laboratory using haptic interface for undergraduate engineering students. Comput. Appl. Eng. Educ. 2016, 24, 508-518. [CrossRef]

10. Jeronymo, D.C.; de Barros Araújo, R.; Coelho, A.A.; Normey-Rico, J.E. An approach for improving student performance in a feedback systems course for process control education. IFAC Proc. Vol. 2014, 47, 10574-10579. [CrossRef]

11. Jara, C.A.; Candelas, F.A.; Puente, S.T.; Torres, F. Hands-on experiences of undergraduate students in Automatics and Robotics using a virtual and remote laboratory. Comput. Educ. 2011, 57, 2451-2461. [CrossRef] 
12. Razali, Z.B.; Trevelyan, J.P. An Evaluation of Students' Practical Intelligence and Ability to Diagnose Equipment Faults. Procedia Soc. Behav. Sci. 2012, 56, 42-51. [CrossRef]

13. Nagai, K. Learning while doing: Practical robotics education. IEEE Robot. Autom. Mag. 2001, 8, 39-43. [CrossRef]

14. Bauer, M.; Brooks, K.S.; Sandrock, C. Industry Expectations and Academic Practice in Control Engineering Education-A South African Survey. IFAC Proc. Vol. 2014, 47, 12226-12231. [CrossRef]

15. Prince, M.J.; Felder, R.M. Inductive Teaching and Learning Methods: Definitions, Comparisons, and Research Bases. J. Eng. Educ. 2006, 95, 123-138. [CrossRef]

16. Bencomo, S.D. Control learning: Present and future. Annu. Rev. Control 2004, 28, 115-136. [CrossRef]

17. Choi, B.; Baek, Y. Exploring factors of media characteristic influencing flow in learning through virtual worlds. Comput. Educ. 2011, 57, 2382-2394. [CrossRef]

18. Soo, M.T.; Aris, H. Game-Based Learning in Requirements Engineering: An Overview. In Proceedings of the 2018 IEEE Conference on e-Learning, e-Management and e-Services (IC3e), Langkawi, Malaysia, 21-22 November 2018; pp. 46-51.

19. Turner, P.E.; Johnston, E.; Kebritchi, M.; Evans, S.; Heflich, D.A. Influence of online computer games on the academic achievement of nontraditional undergraduate students. Cogent Educ. 2018, 5. [CrossRef]

20. Hughes, A. Gamification Versus Serious Games. 2017. Available online: https://trainingindustry.com/articles/learningtechnologies/gamification-versus-serious-games/ (accessed on 26 November 2020).

21. Rieber, L.P.; Smith, L.; Noah, D. The Value of Serious Play. Educ. Technol. 1998, 38, $29-37$.

22. Aldrich, C. Learning by Doing: A Comprehensive Guide to Simulations, Computer Games and Pedagogy in E-learning and Other Educational Experiences; John Wiley \& Sons: San Diego, CA, USA, 2005; ISBN 978-0-7879-7735-1.

23. Meuleners, L.; Fraser, M. A validation study of driving errors using a driving simulator. Transp. Res. Part F Traffic Psychol. Behav. 2015, 29, 14-21. [CrossRef]

24. Mayhew, D.R.; Simpson, H.M.; Wood, K.M.; Lonero, L.; Clinton, K.M.; Johnson, A.G. On-road and simulated driving: Concurrent and discriminant validation. J. Saf. Res. 2011, 42, 267-275. [CrossRef] [PubMed]

25. Underwood, G.; Crundall, D.; Chapman, P. Driving simulator validation with hazard perception. Transp. Res. Part F Traffic Psychol. Behav. 2011, 14, 435-446. [CrossRef]

26. Chan, E.; Pradhan, A.K.; Pollatsek, A.; Knodler, M.A.; Fisher, D.L. Are driving simulators effective tools for evaluating novice drivers' hazard anticipation, speed management, and attention maintenance skills? Transp. Res. Part F Traffic Psychol. Behav. 2010, 13, 343-353. [CrossRef] [PubMed]

27. Casutt, G.; Martin, M.; Keller, M.; Jäncke, L. The relation between performance in on-road driving, cognitive screening and driving simulator in older healthy drivers. Transp. Res. Part F Traffic Psychol. Behav. 2014, 22, 232-244. [CrossRef]

28. Lee, H.C.; Cameron, D.; Lee, A.H. Assessing the driving performance of older adult drivers: On-road versus simulated driving. Accid. Anal. Prev. 2003, 35, 797-803. [CrossRef]

29. Roenker, D.L.; Cissell, G.M.; Ball, K.K.; Wadley, V.G.; Edwards, J.D. Speed-of-Processing and Driving Simulator Training Result in Improved Driving Performance. Hum. Factors J. Hum. Factors Ergon. Soc. 2003, 45, 218-233. [CrossRef]

30. Saleh, L.; Chevrel, P.; Mars, F.; Lafay, J.-F.; Claveau, F. Human-like cybernetic driver model for lane keeping. IFAC Proc. Vol. 2011, 44, 4368-4373. [CrossRef]

31. Sentouh, C.; Chevrel, P.; Mars, F.; Claveau, F. A sensorimotor driver model for steering control. In Proceedings of the 2009 IEEE International Conference on Systems, Man and Cybernetics, San Antonio, TX, USA, 11-14 October 2009; pp. $2462-2467$.

32. Horak, D.T. Experimental Derivation of Models of Human Drivers Executing Emergency Steering Maneuvers. In Proceedings of the ASME 2017 Dynamic Systems and Control Conference, Tysons, VA, USA, 11-13 October 2017; p. V003T33A001.

33. Sarwar, T.; Anastasopoulos, P.C.; Golshani, N.; Hulme, K.F. Grouped random parameters bivariate probit analysis of perceived and observed aggressive driving behavior: A driving simulation study. Anal. Methods Accid. Res. 2017, 13, 52-64. [CrossRef]

34. Hulme, K.F.; Kasprzak, E.M.; Morris, K.L. Correlation of Game-based Experiential Education to Self-reported Driving and Learning Styles. In Proceedings of the MODSIM World Conference, Virginia Beach, VA, USA, 25-27 April 2017.

35. Hulme, K.F.; Androutselis, T.; Eker, U.; Anastasopoulos, P. A Game-based Modeling and Simulation Environment to Examine the Dangers of Task-Unrelated Thought While Driving. In Proceedings of the MODSIM World Conference, Virginia Beach, VA, USA, 26-28 April 2016.

36. Akutagawa, K.; Wakao, Y. Stabilization of Vehicle Dynamics by Tire Digital Control—Tire Disturbance Control Algorithm for an Electric Motor Drive System. World Electr. Veh. J. 2019, 10, 25. [CrossRef]

37. Gillespie, T.D. Fundamentals of Vehicle Dynamics; SAE International: New York, NY, USA, 1992.

38. Milliken, W.F.; Milliken, D.L. Race Car Vehicle Dynamics; SAE: Warrendale, PA, USA, 1995.

39. Hulme, K.F.; Estes, E.; Schiferle, M.; Lim, R. Game-based Learning to Enhance Post-secondary Engineering Training Effectiveness. In Proceedings of the Interservice/Industry Training, Simulation and Education Conference (I/ITSEC), Orlando, FL, USA, 2-6 December 2019.

40. Lampton, C. How Automotive Proving Grounds Work. 2020. Available online: https://auto.howstuffworks.com/automotiveproving-ground.htm (accessed on 14 December 2020).

41. Schmitt, B. Chrysler Fails Moose Test and Breaks First Commandment. The Truth about Cars (Online News Blog). 2012. Available online: http:/ / www.thetruthaboutcars.com/2012/07/chrysler-fails-moose-test-and-breaks-first-commandment/ (accessed on 28 November 2020). 
42. ISO. ISO 3888-2:2011-Passenger Cars-Test Track for a Severe Lane-Change Maneuver-Part 2: Obstacle Avoidance. 2011. Available online: https://www.iso.org/obp/ui/\#iso:std:iso:3888:-2:ed-2:v1:en (accessed on 28 November 2020).

43. Hulme, K.F.; Estes, A.; Schmid, M.; Torres, E.; Hendrick, C.; Sivashangaran, S. Game-based Proving-grounds Simulation to assess Driving \& Learning Preferences. In Proceedings of the Interservice/Industry Training, Simulation and Education Conference (I/ITSEC), Orlando, FL, USA, 2 December 2018.

44. Ackermann, J. Robust decoupling, ideal steering dynamics and yaw stabilization of 4WS cars. Automatics 1994, 30, 1761-1768. [CrossRef]

45. Ackermann, J. Robust Control Prevents Car Skidding. IEEE Control Syst. Mag. 1997, 17, $23-31$.

46. Rajamani, R. Vehicle Dynamics and Control; Springer: New York, NY, USA, 2006; ISBN 0-387-26396-9.

47. Hou, Y.; Wan, J.; Zhao, Y.; Hulme, K.F.; Wu, C.; Sadek, A.W.; Qiao, C. The Effect of Intelligent Speed Control System: An Investigation on Driver's Acceptance and Minimum Headway. In Proceedings of the ITS World Congress, Detroit, MI, USA, 7-11 September 2014.

48. Hou, Y.; Zhao, Y.; Hulme, K.F.; Sadek, A. A Validated and Integrated Simulation Framework for Human Factors Analyses. In Proceedings of the Interservice/Industry Training, Simulation and Education Conference (I/ITSEC), Orlando, FL, USA, 1-5 December 2014.

49. Fountas, G.; Pantangi, S.S.; Hulme, K.F.; Anastasopoulos, P.C. The effects of driver fatigue, gender, and distracted driving on perceived and observed aggressive driving behavior: A correlated grouped random parameters bivariate probit approach. Anal. Methods Accid. Res. 2019, 22, 100091. [CrossRef]

50. Baffet, G.; Charara, A.; Lechner, D. Estimation of vehicle sideslip, tire force and wheel cornering stiffness. Control Eng. Pract. 2009, 17, 1255-1264. [CrossRef]

51. The Review Stories-Understeer vs. Oversteer. Available online: https://thereviewstories.medium.com/understeer-vs-oversteer$90124 \mathrm{db} 12 \mathrm{e} 9 \mathrm{~b}$ (accessed on 20 November 2020).

52. The Clemson University Vehicle Electronics Laboratory-Electronic Stability Control. Available online: https:/ / cecas.clemson. edu/cvel/auto/systems/stability_control.html (accessed on 20 November 2020).

53. Sell, R.; Rüütmann, T.; Seiler, S. Inductive Teaching and Learning in Engineering Pedagogy on the Example of Remote Labs. Int. J. Eng. Pedagog. 2014, 4, 12. [CrossRef]

54. Rice, R.S. Measuring car-driver interaction with the g-g DIAGRAM. SAE Tech. Paper Ser. 1973, 730018. [CrossRef]

55. Deterding, S. Gamification: Designing for motivation. Interactions 2012, 19, 14-17. [CrossRef]

56. Singh, T.; Singhose, W. Input Shaping/Time Delay Control of Maneuvering Flexible Structures. In Proceedings of the 2002 American Control Conference (IEEE Cat. No.CH37301), Anchorage, AK, USA, 8-10 May 2002; pp. 1717-1731.

57. Stott, A.; Neustaedter, C. Analysis of Gamification in Education; Simon Fraser University: Surrey, BC, Canada, 2013.

58. Groeger, J.A.; Banks, A.P. Anticipating the content and circumstances of skill transfer: Unrealistic expectations of driver training and graduated licensing? Ergonomics 2007, 50, 1250-1263. [CrossRef]

59. Stoner, H.A.; Fisher, D.L.; Mollenhauer, M. Simulator and scenario factors influencing simulator sickness. In Handbook of Driving Simulation for Engineering, Medicine, and Psychology; CRC Press: Boca Raton, FL, USA, 2011.

60. Keshavarz, B.; Ramkhalawansingh, R.; Haycock, B.; Shahab, S.; Campos, J. Comparing simulator sickness in younger and older adults during simulated driving under different multisensory conditions. Transp. Res. Part F Traffic Psychol. Behav. 2018, 54, 47-62. [CrossRef] 